\title{
A rational expectations model for simulation and policy evaluation of the Spanish economy
}

\author{
J. E. Boscá · A. Díaz • R. Doménech · J. Ferri • \\ E. Pérez • L. Puch
}

Received: 15 May 2009 / Accepted: 22 October 2009 / Published online: 19 February 2010

(C) The Author(s) 2010. This article is published with open access at Springerlink.com

\begin{abstract}
This paper presents the model used for simulation purposes within the Spanish Ministry of Economic Affairs and Finance. REMS (a Rational Expectations Model for the Spanish economy) is a small open economy dynamic general equilibrium model in the vein of the New-Neoclassical-Keynesian synthesis models, with a strongly micro-founded system of equations. In the long run REMS behaves in accordance with the neoclassical growth model. In the short run, it incorporates nominal, real and financial frictions. Real frictions include adjustment costs in consumption (via habits in consumption and rule-of-thumb households) and investment into physical capital. Due to financial frictions, there is no perfect arbitrage between different types of assets. The model also allows for slow adjustment in wages and price rigidities, which are specified through a Calvo-type Phillips curve. All these modelling choices are fairly in line with other existing models for the Spanish economy. One valuable contribution of REMS to the renewed vintage of $\mathrm{D}(\mathrm{S}) \mathrm{GE}$ models attempting to feature the Spanish economy is the specification of the labour market according to the search paradigm, which is best suited to assess the impact of welfare policies on both the intensive and extensive margins of employment. The model's most valuable asset is the rigour of the analysis of the transmission channels linking policy action with economic outcomes.
\end{abstract}

\footnotetext{
J. E. Boscá · R. Doménech · J. Ferri $(\varangle)$

University of Valencia, Valencia, Spain

e-mail: francisco.ferri@uv.es
}

\author{
A. Díaz · E. Pérez \\ Ministry of Economics and Finance, Madrid, Spain \\ R. Doménech \\ Economic Research Department, BBVA, Madrid, Spain \\ L. Puch \\ FEDEA and ICAE, Universidad Complutense, Madrid, Spain
}


Keywords General equilibrium $\cdot$ Rigidities $\cdot$ Policy simulations

JEL Classification E24 $\cdot$ E32 $\cdot$ E62

\section{Introduction}

REMS is a small open economy dynamic general equilibrium (DGE) model that attempts to feature the main characteristics of the Spanish economy. It builds upon the existing literature on macroeconomic models. ${ }^{1}$ The model is primarily intended to serve as a simulation tool within the Spanish Ministry of Economic Affairs and Finance, with a focus on the economic impact of alternative policy measures over the medium term. REMS' most valuable asset is the rigour of the analysis of the transmission channels linking policy options with economic outcomes.

The small open economy assumption implies that a number of foreign variables are given from the perspective of the national economy and that the magnitude of spillover effects is small. This modelling choice seems to us a fair compromise between realism and tractability.

REMS is in the tradition of DGE models. As such, it departs from MOISEES ${ }^{2}$ in a number of modelling routes. Equations in the model are explicitely derived from intertemporal optimization by representative households and firms under technological, budgetary and institutional constraints. Thus economic decisions are solidly microfounded and any ad hoc dynamics has been avoided. Unlike the traditional Keynesian approach adopted in MOISEES, with backward-looking behaviour strongly focused on the demand side of the economy, REMS is a New Neoclassical-Keynesian synthesis model. Behaviour is predominantly forward-looking and short-term dynamics is embedded into a neoclassical growth model that determines economic developments over the long run. However, since markets do not generally work in a competitive fashion, the levels of employment and economic activity will be lower than those that would prevail in a competitive setting.

In the short run, REMS incorporates nominal, real and financial frictions. Real frictions include adjustment costs in consumption (via the incorporation to the model of habits in consumption and rule-of-thumb households) and investment into physical capital. Due to financial frictions, there is no perfect arbitrage between different types of assets. The model also allows for slow adjustment in wages and price rigidities, which are specified through a Calvo-type Phillips curve. All these modelling choices are fairly in line with other existing models for the Spanish economy. The main contribution of REMS to this renewed vintage of $\mathrm{D}(\mathrm{S}) \mathrm{GE}$ models is the specification

\footnotetext{
1 Many central banks and international institutions have elaborated $\mathrm{D}(\mathrm{S}) \mathrm{GE}$ models. These include, inter alia, SIGMA for the US (Erceg et al. 2006), the BEQM for the UK (Harrison et al. 2005), the TOTEM for Canada (Murchison et al. 2004), AINO for Finland (Kilponen et al. 2004), or the models devised by Smets and Wouters (2003) for EMU, Lindé et al. (2004) for Sweden and Cadiou et al. (2001) for 14 OECD countries. Two models of the Spanish economy different than REMS are BEMOD and MEDEA, respectively developed by Andrés et al. (2006) and Burriel et al. (2007).

2 MOISEES (Modelo de Investigacion y Simulacion de la Economia Española) is the preceding simulation tool available at the Spanish Ministry of Economic Affairs and Finance. See Molinas et al. (1990).
} 
of the labour market according to the search paradigm. This approach has proved successful in providing micro-foundations for equilibrium unemployment in the long run and accounting for both the extensive and intensive margins of employment at business-cycle frequencies. It is therefore best suited to the assessment of welfare policies having an impact on the labour market.

The model is parametrized using Spanish data. To this aim, a database (REMSDB) ${ }^{3}$ has been elaborated that satisfies the model's estimation and calibration requirements and serves to generate a baseline scenario for REMS.

The paper is organized as follows. Section 2 describes in detail the theoretical model. Section 3 discusses the calibration strategy. Section 4 shows the properties of the model by analysing the basic transmission channels following standard simulations. The last section presents the main conclusions.

\section{Theoretical framework}

We model a decentralized, small open economy where households, firms, policymakers and the external sector actively interact each period by trading one final good, government bonds, two primary production factors and one intermediate input. Households are the owners of the available production factors and all the firms operating in the economy. Thus households rent physical capital and labour services out to firms, for which they are paid interest income and wages. In the final goods sector firms produce goods which are imperfect substitutes for goods produced abroad. The intermediate sector is composed of monopolistically competitive firms which produce intermediate varieties employing capital, labour and energy. Job creation is costly in terms of time and real resources. Thus a pure economic rent arises from each job match over which the worker and the firm negotiate in an efficient-bargaining manner.

Each period the government faces a budget constraint where overall expenditure is financed by debt issuance and various distortionary taxes. Intertemporal sustainability of fiscal balance is ensured by a conventional policy reaction function, whereby a lump-sum transfer accommodates the deviation of the debt to GDP ratio from its target level.

Monetary policy is managed by the European Central Bank (ECB) via a Taylor rule, which allows for some smoothness of the interest rate response to the inflation and output gap.

Each household is made of working-age agents who may be active or inactive. In turn, active workers participating in the labour market may either be employed or unemployed. Unemployed agents are actively searching for a job. Firms' investment in vacant posts is endogenously determined and so are job inflows. Finally, job destruction is taken as exogenous.

\footnotetext{
${ }^{3}$ See Boscá et al. (2007), for further details.
} 


\subsection{Consumption behaviour}

A large body of empirical literature documents substantial deviations of consumption from the permanent-income hypothesis. To account for this evidence, we incorporate liquidity-constrained consumers into the standard Keynesian model along the lines of Galí et al. (2007). The household sector consists of a continuum of households of size $N_{t}$. A number $N_{t}^{o}$ of these households has unlimited access to capital markets where they can buy and sell government bonds and accumulate physical capital. These financial transactions enable non-liquidity constrained households to smooth consumption intertemporally in response to changes in the economic environment. The superscript "o" stands for "optimizing consumers". The remaining $N_{t}^{r}$ households is liquidity constrained. These households cannot trade in financial and physical assets and consume out of their disposable income each period. The superscript " $r$ " stands for "rule-of-thumb (RoT) consumers". The size of the working-age population is given by $N_{t}=N_{t}^{o}+N_{t}^{r}$. Let $1-\lambda^{r}$ and $\lambda^{r}$ denote the shares of optimizing and RoT consumers in working age population. Working-age population, optimizing and $R o T$ consumers all grow at the exogenous (gross) rate of $\gamma_{N}=N_{t} / N_{t-1}$, implying that $\lambda^{r}$ is constant over time.

Let $\bar{A}_{t}$ represent the trend component of total factor productivity at time $t$, which will be assumed to grow at the exogenous rate of $\gamma_{A}=\bar{A}_{t} / \bar{A}_{t-1}$. Balanced growth in the model can be ensured by transforming variables in a convenient way. More specifically, any flow variable $X_{t}$ is made stationary through $x_{t} \equiv X_{t} / \bar{A}_{t-1} N_{t-1}$. Similarly, any stock variable $X_{t-1}$ is made stationary through $x_{t-1} \equiv X_{t-1} / \bar{A}_{t-1} N_{t-1}$.

Following Andolfatto (1996) and Merz (1995), we assume that households pool their income and distribute it evenly among its members. This allows households' members to fully insure each other against fluctuations in employment.

\subsubsection{Optimizing households}

Ricardian households face the following maximization programme:

$$
\begin{aligned}
& \max _{\substack{c_{t}^{o}, n_{t}^{o}, j_{t, k}^{o}, k_{t, o}^{o} \\
b_{t}^{o}, b_{t}^{o, e m u}, m_{t}^{o}}} E_{t} \sum_{t=0}^{\infty} \beta^{t}\left[\ln \left(c_{t}^{o}-h^{o} c_{t-1}^{o}\right)+n_{t-1}^{o} \phi_{1} \frac{\left(T-l_{1 t}\right)^{1-\eta}}{1-\eta}\right. \\
& \left.\quad+\left(1-n_{t-1}^{o}\right) \phi_{2} \frac{\left(T-l_{2 t}\right)^{1-\eta}}{1-\eta}+\chi_{m} \ln \left(m_{t}^{o}\right)\right]
\end{aligned}
$$

subject to

$$
\begin{aligned}
& \left(r_{t}\left(1-\tau_{t}^{k}\right)+\tau_{t}^{k} \delta\right) k_{t-1}^{o}+w_{t}\left(1-\tau_{t}^{l}\right)\left(n_{t-1}^{o} l_{1 t}+\overline{r r} s\left(1-n_{t-1}^{o}\right) l_{2 t}\right) \\
& +\left(\left(1-\tau_{t}^{l}\right) g_{s t}-t r h_{t}\right) \\
& +\frac{m_{t-1}^{o}}{1+\pi_{t}^{c}}+\left(1+r_{t-1}^{n}\right) \frac{b_{t-1}^{o}}{1+\pi_{t}^{c}}+\left(1+r_{t-1}^{e m u}\right) \frac{b_{t-1}^{o, e m u}}{1+\pi_{t}^{c}}
\end{aligned}
$$




$$
\begin{gathered}
-\left(1+\tau_{t}^{c}\right) c_{t}^{o} \frac{P_{t}^{c}}{P_{t}}-\frac{P_{t}^{i}}{P_{t}} j_{t}^{o}\left(1+\frac{\phi}{2}\left(\frac{j_{t}^{o}}{k_{t-1}^{o}}\right)\right)-\gamma_{A} \gamma_{N}\left(m_{t}^{o}+b_{t}^{o}+\frac{b_{t}^{o, e m u}}{\phi_{b t}}\right)=0 \\
\gamma_{A} \gamma_{N} k_{t}^{o}=j_{t}^{o}+(1-\delta) k_{t-1}^{o} \\
\gamma_{N} n_{t}^{o}=(1-\sigma) n_{t-1}^{o}+\rho_{t}^{w} s\left(1-n_{t-1}^{o}\right) \\
k_{0}^{o}, n_{0}^{o}, b_{0}^{o}, b_{0}^{o w}, m_{0}^{o}
\end{gathered}
$$

$c_{t}^{o}, n_{t-1}^{o}$ and $s\left(1-n_{t-1}^{o}\right)$ represent, consumption, the employment rate and the unemployment rate of optimizing households; $s$ is the (exogenous) share of the nonemployed workers actively searching for jobs; ${ }^{4} T, l_{1 t}$ and $l_{2 t}$ are total endowment of time, hours worked per employee and hours devoted to job search by the unemployed. $l_{1 t}$ is determined jointly by the firm and the worker as part of the same Nash bargain that is used to determine wages (see Sect. 2.4). $l_{2 t}$ is assumed to be a function of the overall economic activity, so that individual households take it as given. ${ }^{5}$

There are a number of preference parameters defining the utility function of optimizing households. Future utility is discounted at a rate of $\beta \in(0,1)$. The parameter $\eta$ defines the Frisch elasticity of labour supply, which is equal to $\frac{1}{\eta} \cdot h^{o}>0$ indicates that consumption is subject to habits. The subjective value imputed to leisure by workers may vary across employment statuses, and thus $\phi_{1} \neq \phi_{2}$ in general.

For simplicity, we adopt the money-in-the-utility function approach to incorporate money into the model. The timing implicit in this specification assumes that this variable is the household's real money holdings at the end of the period $\left(m_{t}^{o}=\frac{M_{t}^{o}}{P_{t} A_{t} N_{t}^{o}}\right.$ where $P_{t}$ is the aggregate price level), thus after having purchased consumption goods, that yields utility. ${ }^{6}$

The maximization of (1) is constrained as follows. The budget constraint (2) describes the various sources and uses of income. The term $w_{t}\left(1-\tau^{l}\right) n_{t-1}^{o} l_{1 t}$

${ }^{4}$ For simplicity, we assume that the leisure utility of the unemployed searching for a job is the same as for the non-active:

$$
s\left(1-n_{t-1}^{o}\right) \phi_{2} \frac{\left(T-l_{2 t}\right)^{1-\eta}}{1-\eta}=(1-s)\left(1-n_{t-1}^{o}\right) \phi_{3} \frac{\left(T-l_{3 t}\right)^{1-\eta}}{1-\eta} .
$$

5 More specifically, we assume that the search effort undertaken by unemployed workers increases during expansions, depending positively on the GDP growth rate:

$$
l_{2 t}=\left(\overline{l_{2}}\left(\frac{g d p_{t}}{g d p_{t-1}}\right)^{\phi_{e}}\right)^{\left(1-\rho_{e}\right)} l_{2 t-1}^{\rho_{e}}
$$

where $\phi_{e}$ is the elasticity of search effort with respect to the rate of growth of GDP and $\rho_{e}$ captures the strength of inertia in the search effort. The reason for endogeneizing search effort in this way is an empirical one, making possible to obtain a reasonable volatility of vacancies.

6 Carlstrom and Fuerst (2001) have criticized this timing assumption on the grounds that the appropriate way to model the utility from money is to assume that money balances available before going to purchase goods yield utility. However, we follow the standard approach in the literature whereby the end-of-period money holdings yield utility. 
captures net labour income earned by the fraction of employed workers, where $w_{t}$ stands for hourly real wages. The product $\overline{r r} w_{t}\left(1-\tau^{l}\right) s\left(1-n_{t-1}^{o}\right) l_{2 t}$ measures unemployment benefits accruing to the unemployed, where $\overline{r r}$ denotes the replacement rate of the unemployment subsidy to the market wage. Ricardian households hold four kinds of assets, namely private physical capital $\left(k_{t}^{o}\right)$, domestic and euro-zone bonds $\left(b_{t}^{o}\right.$ and $\left.b_{t}^{o, e m u}\right)$ and money balances $\left(M_{t}^{o}\right)$. Barring money, the remaining assets yield some remuneration. As reflected in $r_{t} k_{t-1}^{o}\left(1-\tau^{k}\right)+\tau^{k} \delta k_{t-1}^{o}$, optimizing households pay capital income taxes less depreciation allowances after their earnings on physical capital. Interest payments on domestic and foreign debt are respectively captured by $r_{t-1}^{n} \frac{b_{t-1}^{o}}{1+\pi_{t}^{c}}$, and $r_{t-1}^{e m u} \frac{b_{t-1}^{o, e m u}}{1+\pi_{t}^{c}}$, where $r^{n}$ and $r^{e m u}$ represent the nominal interest rates on domestic and EMU bonds, which differ because of a risk premium (see further below). The remaining two sources of revenues are lump-sum transfers, $t r h_{t}$, and other government transfers, $g_{s t}$.

The household's consumption is given by $\left(1+\tau^{c}\right) \frac{P_{t}^{c}}{P_{t}} c_{t}^{o}$, where $\tau^{c}$ is the consumption income tax. Investment into physical capital, which is affected by increasing marginal costs of installation, is captured by $\frac{P_{t}^{i}}{P_{t}} j_{t}^{o}\left(1+\frac{\phi}{2}\left(\frac{j_{t}}{k_{t-1}}\right)\right)$. Note that the presence in the model of the relative prices $P_{t}^{c} / P_{t}$ and $P_{t}^{i} / P_{t}$ implies that a distinction is made between the three deflators of consumption, investment and aggregate output.

The remaining constraints faced by Ricardian households concern the laws of motion for capital and employment. Each period the private capital stock $k_{t}^{o}$ depreciates at the exogenous rate $\delta$ and is accumulated through investment, $j_{t}^{o}$. Thus, it evolves according to (3). Employment obeys the law of motion (4), where $n_{t-1}^{o}$ and $s\left(1-n_{t-1}^{o}\right)$ respectively denote the share of employed and unemployed optimizing workers in the economy at the end of period $t-1$. Each period employment is destroyed at the exogenous rate $\sigma$ and new employment opportunities come at the rate $\rho_{t}^{w}$, which represents the probability that one unemployed worker will find a job. Although the job-finding rate $\rho_{t}^{w}$ is taken as given by individual workers, it is endogenously determined at the aggregate level according to the following Cobb-Douglas matching function: ${ }^{7}$

$$
\rho_{t}^{w} s\left(1-n_{t-1}\right)=\vartheta_{t}\left(v_{t}, n_{t-1}\right)=\chi_{1} v_{t}^{\chi_{2}}\left[s\left(1-n_{t-1}\right) l_{2 t}\right]^{1-\chi_{2}}
$$

Finally, $k_{0}^{o}, n_{0}^{o}, b_{0}^{o}, b_{0}^{o, e m u}, m_{0}^{o}$ in (4) represent the initial conditions for all stock variables entering the maximization problem.

The solution to the optimization programme above generates the following first order conditions for consumption, employment, investment, capital stock, government debt, foreign debt and money holdings:

$$
\lambda_{1 t}^{o}=\frac{1}{\left(P_{t}^{c} / P_{t}\right)\left(1+\tau_{t}^{c}\right)}\left(\frac{1}{c_{t}^{o}-h^{o} c_{t-1}^{o}}-\beta \frac{h^{o}}{c_{t+1}^{o}-h^{o} c_{t}^{o}}\right)
$$

\footnotetext{
7 Note that this specification presumes that all workers are identical to the firm.
} 


$$
\begin{gathered}
\gamma_{N} \lambda_{3 t}^{o}=\beta E_{t}\left\{\begin{array}{c}
\phi_{1} \frac{\left(T-l_{1 t+1}\right)^{1-\eta}}{1-\eta}-\phi_{2} \frac{\left(T-l_{2 t+1}\right)^{1-\eta}}{1-\eta} \\
+\lambda_{1 t+1}^{o} w_{t+1}\left(1-\tau_{l+1}^{l}\right)\left(l_{1 t+1}-\overline{r r} s l_{2 t+1}\right) \\
+\lambda_{3 t+1}^{o}\left[(1-\sigma)-\rho_{t+1}^{w}\right]
\end{array}\right\} \\
\gamma_{A} \gamma_{N} \frac{\lambda_{2 t}^{o}}{\lambda_{1 t}^{o}}=\beta E_{t} \frac{\lambda_{1 t+1}^{o}}{\lambda_{1 t}^{o}}\left\{\left[r_{t+1}\left(1-\tau_{t+1}^{k}\right)+\tau_{t+1}^{k} \delta\right]\right. \\
\left.+\frac{\phi}{2} \frac{P_{t+1}^{i}}{P_{t+1}} \frac{j_{t+1}^{o 2}}{k_{t}^{o 2}}+\frac{\lambda_{2 t+1}^{o}}{\lambda_{1 t+1}^{o}}(1-\delta)\right\} \\
\lambda_{2 t}^{o}=\lambda_{1 t}^{o} \frac{P_{t}^{i}}{P_{t}}\left[1+\phi\left(\frac{j_{t}^{o}}{k_{t-1}^{o}}\right)\right] \\
\gamma_{A} \gamma_{N} E_{t} \frac{\lambda_{1 t}^{o}}{\lambda_{1 t+1}^{o}}=\beta E_{t} \frac{1+r_{t}^{n}}{1+\pi_{t+1}^{c}} \\
\gamma_{A} \gamma_{N} \lambda_{1 t}^{o} \frac{1}{\phi_{b t}}=\beta E_{t} \frac{\lambda_{1 t+1}^{o}\left(1+r_{t}^{e m u}\right)}{1+\pi_{t+1}^{c}} \\
\frac{\chi_{m}}{m_{t}^{o}}=\gamma_{A} \gamma_{N} \lambda_{1 t}^{o} \frac{r_{t}^{n}}{1+r_{t}^{n}}
\end{gathered}
$$

as well as the three households' restrictions (2), (3) and (4).

Due to the presence of habits in consumption, Eq. (7) evaluates the current-value shadow price of income in terms of the difference between the marginal utility of consumption in two consecutive periods $t$ and $t+1$.

Equation (8) ensures that the intertemporal reallocation of labour supply cannot improve the life-cycle household's utility. This optimizing rule is a distinctive feature of search models and substitutes for the conventional labour supply in the competitive framework. It tells us that as search is a costly process there is a premium on being employed, $\lambda_{3 t}^{o}$, which measures the marginal contribution of a newly created job to the household's utility. As such, $\lambda_{3 t}^{o}$ includes three terms. The first term on the right-hand side of (8) represents the difference between the value imputed to leisure by an employed and an unemployed worker. The second term captures the present discounted value of the cash-flow generated by the new job in $t+1$, defined as the after-tax labour income minus the foregone after-tax unemployment benefits. The current-value shadow price of income, $\lambda_{1 t+1}^{o}$, evaluates this cash-flow according to its purchasing power in terms of consumption. The third term represents the capital value in $t+1$ of an additional employed worker corrected for the probability that the new job will be destroyed between $t$ and $t+1$.

Expression (9) ensures that the intertemporal reallocation of capital cannot improve the household's utility. $\frac{\lambda_{2 t}^{o}}{\lambda_{1 t}^{o}}$ denotes the current-value shadow price of capital. This arbitrage condition includes two terms. The first term represents the present discounted value of its cash-flow in $t+1$, defined as the sum of rental cost net of taxes, depreciation allowances and total adjustment costs evaluated in terms of consumption. The second term represents the present value in $t+1$ of an additional unit of productive capital corrected for the depreciation rate. 
Equation (10) states that investment is undertaken until the opportunity cost of a marginal increase in investment in terms of consumption is equal to its marginal expected contribution to the household's utility.

The marginal utility of consumption evolves according to expression (11), which is obtained by deriving the Lagrangian with respect to domestic government bonds $b_{t}^{o}$. (11) and (7) jointly yield the Euler condition for consumption.

Expression (12) is obtained by deriving the Lagrangian with respect to foreign debt $b_{t}^{o, e m u}$. Note that the specification above assumes that there is no perfect arbitrage between domestic and foreign bonds. This line is taken in Turnovsky (1985), Benigno (2001), Schmitt-Grohe and Uribe (2003) or Erceg et al. (2005), as a means to ensure that net foreign assets are stationary. When taking a position in the international bonds market, optimizing households face a financial intermediation risk premium $\left(\phi_{b t}\right)$ which depends on net holdings of internationally traded bonds. The risk premium is therefore modelled as follows

$$
\ln \phi_{b t}=-\phi_{b}\left(\exp \left(b_{t}^{o, e m u}\right)-1\right)
$$

The rest of the section simply rearranges first order conditions to facilitate the economic interpretation of Ricardian households' behaviour. In order to obtain the arbitrage relation between domestic and foreign bonds we proceed to combine (12) with (11). This algebra yields

$$
1+r_{t}^{n}=\phi_{b t}\left(1+r_{t}^{n w}\right)
$$

which is the interest parity condition modified to incorporate the effect of the risk premium. Note also that (15) differs from the standard uncovered interest parity condition in that there is no risk associated with exchange rate movements, as both domestic and foreign bonds are expressed in the same currency. ${ }^{8}$

To obtain the arbitrage relation between physical capital and government bonds it is convenient to define $q_{t} \equiv \lambda_{2 t}^{o} / \lambda_{1 t}^{o}$, which allows us to rewrite Eq. (9) as

$$
q_{t}=\frac{1+\pi_{t+1}^{c}}{1+r_{t}^{n}}\left[r_{t+1}\left(1-\tau_{t+1}^{k}\right)+\tau_{t+1}^{k} \delta+\frac{\phi}{2} \frac{j_{t+1}^{2}}{k_{t}^{2}}+q_{t+1}(1-\delta)\right]
$$

\footnotetext{
8 For simplicity, it is assumed that foreign bonds are expressed in euros. We could assume instead that some bonds could be from the rest of the world, expressed in a foreign currency. In this case, the uncovered interest rate parity for the euro area ensures that

$$
1+r_{t}^{e m u}=E_{t} \frac{e r_{t+1}}{e r_{t}}\left(1+r_{t}^{w}\right)
$$

where $e r$ is the nominal exchange rate. Given the relative small size of Spain in EMU, we assume that the euro exchange rate with the rest of the world is unaffected by Spanish variables, even though Spanish inflation has a small influence on ECB interest rates. This assumption is additionally supported by the empirical evidence since, as documented by many authors (see, for example, Adolfson et al. 2007, and the references there in), the unconvered interest parity condition cannot account for the forward premium puzzle shown by the data. For these reasons, all foreign prices, including those of foreign bonds, are taken to be exogenous and are expressed in euros.
} 
This is a Fisher-type condition in a context characterized by adjustment costs of installation of physical capital. In order to see this more clearly let $\phi=0$, implying that the investment process is not subject to any installation costs. In this case, (10) simplifies to $q_{t}=q_{t+1}=1$ and expression (16) becomes

$$
E_{t}\left[1+\left(r_{t+1}-\delta\right)\left(1-\tau^{k}\right)\right]=E_{t}\left(\frac{1+r_{t+1}^{n}}{1+\pi_{t+1}^{c}}\right)
$$

which is the conventional Fisher parity condition.

Finally, expression (13) can be easily rewritten as a money demand function by using the current-value shadow price of income (7):

$$
m_{t}^{o}=\frac{1}{\gamma_{A} \gamma_{N}} \chi_{m}\left(1+\tau_{t}^{c}\right) \frac{P_{t}^{c}}{P_{t}} \frac{1+r_{t}^{n}}{r_{t}^{n}} \frac{1}{\left(\frac{1}{c_{t}^{o}-h^{o} c_{t-1}^{o}}-\beta \frac{h^{o}}{c_{t+1}^{o}-h^{o} c_{t}^{o}}\right)}
$$

\subsubsection{Rule-of-thumb households}

RoT households do not have access to capital markets, so that they face the following maximization programme:

$$
\begin{aligned}
& \max _{c_{t}^{r}, n_{t}^{r}} E_{t} \sum_{t=0}^{\infty} \beta^{t} \\
& \quad \times\left[\ln \left(c_{t}^{r}-h^{r} c_{t-1}^{r}\right)+n_{t-1}^{r} \phi_{1} \frac{\left(T-l_{1 t}\right)^{1-\eta}}{1-\eta}+\left(1-n_{t-1}^{r}\right) \phi_{2} \frac{\left(T-l_{2 t}\right)^{1-\eta}}{1-\eta}\right]
\end{aligned}
$$

subject to the law of motion of employment (4) and the specific liquidity constraint whereby each period's consumption expenditure must be equal to current labour income and government transfers, as reflected in:

$$
\begin{gathered}
w_{t}\left(1-\tau_{t}^{l}\right)\left(n_{t-1}^{r} l_{1 t}+\overline{r r} s\left(1-n_{t-1}^{r}\right) l_{2 t}\right) \\
+g_{s t}\left(1-\tau_{t}^{l}\right)-t r h_{t}-\left(1+\tau_{t}^{c}\right) c_{t}^{r} \frac{P_{t}^{c}}{P_{t}}=0 \\
\gamma_{N} n_{t}^{r}=(1-\sigma) n_{t-1}^{r}+\rho_{t}^{w} s\left(1-n_{t-1}^{r}\right) \\
n_{0}^{r}
\end{gathered}
$$

where $n_{0}^{r}$ represents the initial aggregate employment rate, which is the sole stock variable in the above programme. Note that RoT consumers do not save, thus they do not hold any assets. This feature of RoT consumers considerably simplifies the solution to the optimization programme, which is characterized by the following equations for optimal consumption $c_{t}^{r}$ and optimal employment, $n_{t}^{r}$ : 


$$
\begin{gathered}
\lambda_{1 t}^{r}=\frac{1}{\left(P_{t}^{c} / P_{t}\right)\left(1+\tau_{t}^{c}\right)}\left(\frac{1}{c_{t}^{r}-h^{r} c_{t-1}^{r}}-\beta \frac{h^{r}}{c_{t+1}^{r}-h^{r} c_{t}^{r}}\right) \\
\gamma_{N} \lambda_{3 t}^{r}=\beta E_{t}\left\{\begin{array}{c}
\phi_{1} \frac{\left(T-l_{1 t+1}\right)^{1-\eta}}{1-\eta}-\phi_{2} \frac{\left(T-l_{2 t}\right)^{1-\eta}}{1-\eta} \\
+\lambda_{1 t+1}^{r} w_{t+1}\left(1-\tau_{l+1}^{l}\right)\left(l_{1 t+1}-\overline{r r} s l_{2 t+1}\right) \\
+\lambda_{3 t+1}^{r}\left[(1-\sigma)-\rho_{t+1}^{w}\right]
\end{array}\right\}
\end{gathered}
$$

Noteworthy, the optimizing behaviour of RoT households preserves the dynamic structure of the model, due to consumption habits and the dynamic nature of the employment decision.

\subsubsection{Aggregation}

Aggregate consumption and employment can be defined as a weighted average of the corresponding variables for each household type:

$$
\begin{aligned}
& c_{t}=\left(1-\lambda^{r}\right) c_{t}^{o}+\lambda^{r} c_{t}^{r} \\
& n_{t}=\left(1-\lambda^{r}\right) n_{t}^{o}+\lambda^{r} n_{t}^{r}
\end{aligned}
$$

For the variables that exclusively concern Ricardian households, aggregation is performed as:

$$
\begin{aligned}
k_{t} & =\left(1-\lambda^{r}\right) k_{t}^{o} \\
j_{t} & =\left(1-\lambda^{r}\right) j_{t}^{o} \\
b_{t} & =\left(1-\lambda^{r}\right) b_{t}^{o} \\
b_{t}^{e m u} & =\left(1-\lambda^{r}\right) b_{t}^{o, e m u} \\
m_{t} & =\left(1-\lambda^{r}\right) m_{t}^{o}
\end{aligned}
$$

\subsection{Factor demands}

Production in the economy takes place at two different levels. At the lower level, an infinite number of mopolistically competing firms produce differentiated intermediate goods $y_{i}$, which imperfectly substitute each other in the production of the final good. These differentiated goods are then aggregated by competitive retailers into a final domestic good ( $y$ ) using a CES aggregator.

Intermediate producers solve a two-stage problem. In the first stage, each firm faces a cost minimization problem which results in optimal demands for production factors. When choosing optimal streams of capital, energy, employment and vacancies, intermediate producers set prices by varying the mark-up according to demand conditions. Variety producer $i \in(0,1)$ uses three inputs, namely, a CES composite input of private 
capital and energy, labour and public capital. Technology possibilities are given by:

$$
y_{i t}=z_{i t}\left\{\left[a k_{i t-1}^{-\rho}+(1-a) e_{i t}^{-\rho}\right]^{-\frac{1}{\rho}}\right\}^{1-\alpha}\left(n_{i t-1} l_{i 1 t}\right)^{\alpha}\left(k_{i t-1}^{p}\right)^{\zeta}
$$

where all variables are scaled by the trend component of total factor productivity and $z_{t}$ represents a transitory technology shock. Each variety producer rents physical capital, $k_{t-1}$, and labour services, $n_{t-1} l_{1 t}$, from households, and uses public capital services, $k_{t-1}^{p}$, provided by the government. Intermediate energy inputs $e_{t}$ can be either imported from abroad or produced at home. The elasticity of substitution between private capital and energy is given by $\frac{1}{1+\rho} . a \in(0,1)$ is a distribution parameter which determines relative factor shares in the steady state. For the sake of clarity, let us denote capital services by $k_{i e t}$ as:

$$
k_{i e t}=\left[a k_{i t-1}^{-\rho}+(1-a) e_{i t}^{-\rho}\right]^{-\frac{1}{\rho}}
$$

Note that if $\rho=0$ expression (32) simplifies to the Cobb-Douglas case. Our specification is more general, i.e., private capital and energy can be seen as either complements $(\rho>0)$ or more substitutes than Cobb-Douglas $(\rho<0)$, depending on the value of $\rho$. Our calibration strategy will nevertheless pin down the value of $\rho$ so as to ensure that the elasticity of substitution between private capital and energy is smaller than the elasticity of substitution between the capital-energy composite and labour.

Factor demands are obtained by solving the cost minimization problem faced by each variety producer (we drop the industry index $i$ when no confusion arises)

$\min _{k_{t}, n_{t}, v_{t}, e_{t}} E_{t} \sum_{t=0}^{\infty} \beta^{t} \frac{\lambda_{1 t+1}^{o}}{\lambda_{1 t}^{o}}\left(r_{t} k_{t-1}+w_{t}\left(1+\tau^{s c}\right) n_{t-1} l_{1 t}+\kappa_{v} v_{t}+\frac{P_{t}^{e}}{P_{t}} e_{t}\left(1+\tau^{e}\right)\right)$

subject to

$$
\begin{gathered}
y_{t}=z_{i t}\left(\left[a k_{t-1}^{-\rho}+(1-a) e_{t}^{-\rho}\right]^{-\frac{1}{\rho}}\right)^{1-\alpha}\left(n_{t-1} l_{1 t}\right)^{\alpha}\left(k_{t-1}^{p}\right)^{\zeta} \\
\gamma_{N} n_{t}=(1-\sigma) n_{t-1}+\rho_{t}^{f} v_{t} \\
n_{0}
\end{gathered}
$$

where, in accordance with the ownership structure of the economy, future profits are discounted at the household relevant rate $\beta \frac{\lambda_{1 t+1}^{o}}{\lambda_{1 t}^{o}} . \kappa_{v}$ captures recruiting costs per vacancy, $\tau^{s c}$ is the social security tax rate levied on gross wages, and $\rho_{t}^{f}$ is the probability that a vacancy will be filled in any given period $t$. It is worth noting that the probability of filling a vacant post $\rho_{t}^{f}$ is exogenously taken by the firm. However, from 
the perspective of the overall economy, this probability is endogenously determined according to the following Cobb-Douglas matching function:

$$
\rho_{t}^{w} s\left(1-n_{t-1}\right)=\rho_{t}^{f} v_{t}=\chi_{1} v_{t}^{\chi_{2}}\left[s\left(1-n_{t-1}\right) l_{2 t}\right]^{1-\chi_{2}}
$$

Under the assumption of symmetry, the solution to the optimization programme above generates the following first order conditions for private capital, employment, energy and the number of vacancies

$$
\begin{gathered}
r_{t+1}=(1-\alpha) m c_{t+1} \frac{y_{t+1}}{k_{e t+1}} a\left(\frac{k_{e t+1}}{k_{t}}\right)^{1+\rho} \\
\gamma_{N} \lambda_{t}^{n d}=\beta E_{t} \frac{\lambda_{1 t+1}^{o}}{\lambda_{1 t}^{o}}\left(\alpha m c_{t+1} \frac{y_{t+1}}{n_{t}}-w_{t+1}\left(1+\tau_{t+1}^{s c}\right) l_{1 t+1}+\lambda_{t+1}^{n d}(1-\sigma)\right) \\
(1-\alpha)(1-a) m c_{t} \frac{y_{t}}{k_{e t-1}}\left(\frac{k_{e t}}{e_{t}}\right)^{1+\rho}=\frac{P_{t}^{e}}{P_{t}}\left(1+\tau_{t}^{e}\right) \\
\kappa_{v} v_{t}=\lambda_{t}^{n d} \chi_{1} v_{t}^{\chi_{2}}\left(s\left(1-n_{t-1}\right) l_{2 t}\right)^{1-\chi_{2}}
\end{gathered}
$$

where the real marginal cost $\left(m c_{t}\right)$ corresponds to the Lagrange multiplier associated with the first restriction (34), whereas $\lambda_{t}^{\text {nd }}$ denotes the Lagrange multiplier associated with the second restriction (35).

The demand for private capital is determined by (38). It is positively related to the marginal productivity of capital $(1-\alpha) \frac{y_{t+1}}{k_{e t+1}} a\left(\frac{k_{e t+1}}{k_{t}}\right)^{1+\rho}$ times the firm's marginal cost $m c_{t+1}{ }^{9}$ which, in equilibrium, must equate the gross return on physical capital.

The intertemporal demand for labour (39) requires the marginal contribution to profits of a new job to be equal to the marginal product net of the wage rate plus the capital value of the new job in $t+1$, corrected for the job destruction rate between $t$ and $t+1$.

Energy demand is defined by (40). It is positively related to the marginal productivity of energy $(1-\alpha)(1-a) \frac{y_{t}}{k_{e t-1}}\left(\frac{k_{e t}}{e_{t}}\right)^{1+\rho}$ times the marginal cost $m c_{t}$ which, in equilibrium, must equate the real price of energy including energy taxes.

Expression (41) reflects that firms choose the number of vacancies in such a way that the marginal recruiting cost per vacancy, $\kappa_{v}$, is equal to its expected present value, $\lambda_{t}^{n d} \frac{\chi_{1} v_{t}^{\chi_{2}}\left(s\left(1-n_{t-1}\right) l_{2 t}\right)^{1-\chi_{2}}}{v_{t}}$, where $\lambda_{t}^{n d}$ denotes the shadow price of an additional worker, and $\frac{\chi_{1} v_{t}^{\chi_{2}}\left(s\left(1-n_{t-1}\right) l_{2 t}\right)^{1-\chi_{2}}}{v_{t}}$ is the transition probability from an unfilled to a filled vacancy.

\footnotetext{
${ }^{9}$ Under imperfect competition conditions, cost minimization implies that production factors are remunerated by the marginal revenue times their marginal productivity. In our specification for factor demands, the marginal revenue has been replaced by the corresponding marginal costs. We are legitimated to proceed in this manner because in equilibrium these two marginal concepts are made equal by the imperfectly competitive firm.
} 
2.3 Pricing behaviour of intermediate firms: the New Phillips curve

Since each firm $y_{i}$ produces a variety of domestic good which is an imperfect substitute for the varieties produced by other firms, it acts as a monopolistic competitor facing a downward-sloping demand curve of the form:

$$
y_{i t}=y_{t}\left(\frac{P_{i t}}{P_{t}}\right)^{-\varepsilon}
$$

where $\left(\frac{P_{i t}}{P_{t}}\right)$ is the relative price of variety $y_{i}, \varepsilon=(1+\varsigma) / \varsigma$, where $\varsigma \geq 0$ is the elasticity of substitution between intermediate goods, and $y_{t}$ represents the production of the final good which combines varieties of differentiated intermediate inputs as follows

$$
y_{t}=\left(\int_{0}^{1} y_{i t}^{1 / 1+\varsigma} d i\right)^{1+\varsigma} \text { and } P_{t}=\left(\int_{0}^{1} P_{i t}^{-\frac{1}{\varsigma}} d i\right)^{-\varsigma}
$$

Variety producers act as monopolists and set prices when allowed. As in Calvo hypothesis (Calvo 1983) we assume overlapping price adjustment. Each period, a proportion $\theta$ of non-optimizing firms index prices to lagged inflation, according to the rule $P_{i t}=\left(1+\pi_{t-1}\right)^{\varkappa} P_{i t-1}$ (with $\varkappa$ representing the degree of indexation); a measure $1-\theta$ of firms set their prices $\widetilde{P}_{i t}$ optimally, i.e., to maximize the present value of expected profits. Consequently, $1-\theta$ represents the probability of adjusting prices each period, whereas $\theta$ can be interpreted as a measure of price rigidity. Thus, the maximization problem of the representative variety producer can be written as:

$$
\max _{\widetilde{P}_{i t}} E_{t} \sum_{j=0}^{\infty} \rho_{i t, t+j}(\beta \theta)^{j}\left[\widetilde{P}_{i t} \bar{\pi}_{t+j} y_{i t+j}-P_{t+j} m c_{i t, t+j} y_{i t+j}\right]
$$

subject to

$$
y_{i t+j}=\left(\widetilde{P}_{i t} \bar{\pi}_{t+j}\right)^{-\varepsilon} P_{t+j}^{\varepsilon} y_{t+j}
$$

where $\widetilde{P}_{i t}$ is the price set by the optimizing firm at time $t, \beta$ is the discount factor, $m c_{t, t+j}$ represents the marginal cost at $t+j$ of the firm that last set its price in period $t, \bar{\pi}_{t+j}=\prod_{h=1}^{j}\left(1+\pi_{t+h-1}\right)^{\varkappa} \cdot \rho_{t, t+j}$, a price kernel which captures the marginal utility of an additional unit of profits accruing to Ricardian households at $t+j$, is given by

$$
\frac{E_{t} \rho_{t, t+j}}{E_{t} \rho_{t, t+j-1}}=\frac{E_{t}\left(\lambda_{1 t+j}^{o} / P_{t+j}\right)}{E_{t}\left(\lambda_{1 t+j-1}^{o} / P_{t+j-1}\right)}
$$


The first order condition of the optimization problem above is

$$
\widetilde{P}_{i t}=\frac{\varepsilon}{\varepsilon-1} \frac{\sum_{j=0}^{\infty}(\beta \theta)^{j} E_{t}\left[\rho_{i t, t+j} P_{t+j}^{\varepsilon+1} m c_{i t+j} y_{t+j} \bar{\pi}_{t+j}^{-\varepsilon}\right]}{\sum_{j=0}^{\infty}(\beta \theta)^{j} E_{t}\left[\rho_{i t, t+j} P_{t+j}^{\varepsilon} y_{t+j} \bar{\pi}_{t+j}^{(1-\varepsilon)}\right]}
$$

and the corresponding aggregate price index is equal to

$$
P_{t}=\left[\theta\left(\pi_{t-1}^{\varkappa} P_{t-1}\right)^{1-\varepsilon}+(1-\theta) \widetilde{P}_{t}^{1-\varepsilon}\right]^{\frac{1}{1-\varepsilon}}
$$

As standard in the literature, ${ }^{10}$ Eq. (48) can be used to obtain an expression for aggregate inflation of the form:

$$
\pi_{t}=\frac{\beta}{1+\varkappa \beta} E_{t} \pi_{t+1}+\frac{(1-\beta \theta)(1-\theta)}{\theta(1+\varkappa \beta)} \widehat{m c}_{t}+\frac{\varkappa}{1+\varkappa \beta} \pi_{t-1}
$$

where $\widehat{m c}_{t}$ in $m c_{t}=\frac{\varepsilon-1}{\varepsilon}\left(1+\widehat{m c}_{t}\right)$ measures the deviation of the firm's marginal cost from the steady state. Equation (49) is known in the literature as the New Phillips Curve. It participates of the conventional Phillips-curve philosophy that inflation is influenced by activity in the short run. However, the New Phillips Curve emphasizes real marginal costs as the relevant variable to the inflation process, which is in turn seen as a forward-looking phenomenon. This is so because when opportunities to adjust prices arrive infrequently, a firm will be concerned with future inflation. A second departure of the New Phillips curve from the traditional one is that it is derived from the optimizing behaviour of firms. This makes it possible to define the marginal cost elasticity of inflation, $\lambda$, as a function of the structural parameters in the model, $\beta$ and $\theta$ :

$$
\lambda=\frac{(1-\beta \theta)(1-\theta)}{\theta(1+\varkappa \beta)}
$$

Equation (50) shows that an increase in the average time spell between price changes, $\theta$, makes current inflation less responsive to $\widehat{m c}_{t}$. Output movements will therefore have a smaller impact on current inflation, holding expected future inflation constant. The reduced form of the New Phillips curve can be written as:

$$
\pi_{t}=\beta^{f} E_{t} \pi_{t+1}+\lambda \widehat{m c}_{t}+\beta^{b} \pi_{t-1}
$$

Notice that, for the sake of simplicity, the model neglects the influence of the distribution of prices (implicit in the Calvo hypothesis) in equilibrium. However, as shown by Burriel et al. (2007) in a DGE setting with nominal rigidities, such simplifying assumption affects the explanatory power of the model neither dynamically nor in the steady state.

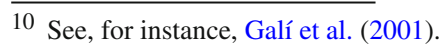




\subsection{Trade in the labour market: the labour contract}

The key departure of search models from the competitive paradigm is that trading in the labour market is subject to transaction costs. Each period, the unemployed engage in search activities in order to find vacant posts spread over the economy. Costly search in the labour market implies that there are simultaneous flows into and out of the state of employment, thus an increase (reduction) in the stock of unemployment takes place whenever job destruction (creation) predominates over job creation (destruction). Therefore unemployment stabilizes if inflows and outflows cancel out one another, i.e.,

$$
\rho_{t}^{f} v_{t}=\rho_{t}^{w} s\left(1-n_{t-1}\right)=\chi_{1} v_{t}^{\chi_{2}}\left[\left(1-n_{t-1}\right) l_{2 t}\right]^{1-\chi_{2}}=(1-\sigma) n_{t-1}
$$

Because it takes time (for households) and real resources (for firms) to make profitable contacts, some pure economic rent emerges with each new job, which is equal to the sum of the expected search costs the firm and the worker will further incur if they refuse to match. The presence of such rents gives rise to a bilateral monopoly framework, whereby both parties cooperate for a win-win job match, but compete for the share of the overall surplus.

Several wage and hours determination schemes can be applied to a bilateral monopoly framework. In particular, we will assume that firms and workers negotiate a labour contract in hours and wages in an efficient-bargaining manner. As discussed by Pissarides (2000, ch. 7, p. 176), hours of work may be determined either by the worker in such a way as to maximize his utility or by a bargain between the firm and the worker. The efficient number of hours is nevertheless determined by a Nash bargain. If workers choose their own hours of work, they will choose to work too few hours. The reason of this inefficiency is related to the existence of search costs. ${ }^{11}$

Note that, because homogeneity holds across all job-worker pairs in the economy, the outcome of this negotiation will be the same everywhere. However an individual firm and worker are too small to influence the market. As a result when they meet they negotiate the terms of the contract by taking as given the behaviour in the rest of the market. The outcome of the bargaining process maximizes the weighted individual surpluses from the match

$$
\max _{w_{t+1}, l_{1 t+1}}\left[\lambda^{r} \frac{\lambda_{3 t}^{r}}{\lambda_{1 t}^{r}}+\left(1-\lambda^{r}\right) \frac{\lambda_{3 t}^{o}}{\lambda_{1 t}^{o}}\right]^{\lambda^{w}}\left(\lambda_{t}^{n d}\right)^{\left(1-\lambda^{w}\right)}
$$

where $\lambda^{w} \in(0,1)$ reflects the worker's bargaining power. The two terms in brackets reflect the worker's and firm's surpluses from the bargain. $\lambda_{3 t}^{o} / \lambda_{1 t}^{o}$ and $\lambda_{3 t}^{r} / \lambda_{1 t}^{r}$ respectively denote the earning premium of employment over unemployment for a Ricardian and a $R o T$ worker. Similarly, $\lambda_{t}^{\text {nd }}$ represents the profit premium of a filled over an unfilled vacancy for the representative firm. Note that this bargaining scheme features the same wage for all workers, irrespective of whether they are Ricardian or RoT.

${ }^{11}$ See also Trigari (2004) for further details about the implications of using alternatively the so called right-to-manage hypothesis. 
Efficient real wage and hours worked (53) satisfy the following conditions:

$$
\begin{aligned}
& w_{t}\left(1-\tau^{l}\right) l_{1 t}=\lambda^{w}\left[\frac{\left(1-\tau^{l}\right)}{\left(1+\tau^{s c}\right)} \alpha m c_{t} \frac{y_{t}}{n_{t-1}}+\frac{\left(1-\tau^{l}\right)}{\left(1+\tau^{s c}\right)} \frac{\kappa_{v} v_{t}}{\left(1-n_{t-1}\right)}\right] \\
& +\left(1-\lambda^{w}\right)\left[\left(\frac{\left(1-\lambda^{r}\right)}{\lambda_{1 t}^{o}}+\frac{\lambda^{r}}{\lambda_{1 t}^{r}}\right)\left(\phi_{2} \frac{\left(1-l_{2}\right)^{1-\eta}}{1-\eta}-\phi_{1} \frac{\left(1-l_{1 t}\right)^{1-\eta}}{1-\eta}\right)+\left(1-\tau^{l}\right) g_{u t}\right] \\
& +\left(1-\lambda^{w}\right)\left(1-\sigma-\rho_{t}^{w}\right) \lambda^{r} \beta E_{t} \frac{\lambda_{3 t+1}^{r}}{\lambda_{1 t+1}^{r}}\left(\frac{\lambda_{1 t+1}^{o}}{\lambda_{1 t}^{o}}-\frac{\lambda_{1 t+1}^{r}}{\lambda_{1 t}^{r}}\right)
\end{aligned}
$$

$$
\frac{\left(1-\tau^{l}\right)}{\left(1+\tau^{s c}\right)} \alpha m c_{t} \frac{y_{t}}{n_{t-1} l_{1 t}}=\phi_{1}\left(T-l_{1 t}\right)^{-\eta}\left[\frac{1-\lambda^{r}}{\lambda_{1 t}^{o}}+\frac{\lambda^{r}}{\lambda_{1 t}^{r}}\right]
$$

where we see that the equilibrium wage in a search framework is a weighted average between the highest feasible wage (i.e., the marginal productivity of labour augmented by the expected hiring cost per unemployed worker) and the lowest acceptable wage (i.e., the reservation wage, as given by the second and third terms in the right-hand side of (54)). Weights are given by the parties' bargaining power in the negotiation, $\lambda^{w}$ and $\left(1-\lambda^{w}\right)$. Notice that when $\lambda^{r}=0$, all consumers are Ricardian, and, therefore, the solutions for the wage rate and hours simplify to the standard ones (see Andolfatto 1996).

Putting aside for the moment the last term in the right-hand side of (54), the outside option (i.e., the reservation wage) is given, first, by the gap between the value imputed to leisure by an unemployed and by an employed worker. This gap is, in turn, a weighted average of the valuation of leisure by Ricardian and $R o T$ workers, that differ in their marginal utilities of consumption $\left(\lambda_{1 t}^{o}\right.$ and $\left.\lambda_{1 t}^{r}\right)$. Notice that the higher the marginal utility of consumption is, the higher the willingness of workers to accept relatively lower wages. Second, the reservation wage also depends on unemployment benefits $\left(g_{u t}\right)$. An increase in the replacement rate improves the worker's threat point in the bargain process and exercites upward pressure to the bargained wage.

The third term in the right-hand side of (54) is a part of the reservation wage that depends only on the existence of $R o T$ workers (only if $\lambda^{r}>0$ this term is different from zero). It can be interpreted as an inequality term in utility. The economic intuition is as follows: RoT consumers are not allowed to use their wealth to smooth consumption over time, but they can take advantage of the fact that a matching today continues with some probability $(1-\sigma)$ in the future, yielding a labour income that, in turn, will be used to consume tomorrow. Therefore, they use the margin that hours and wage negotiation provides them to improve their lifetime utility, by narrowing the gap in utility with respect to Ricardian consumers. In this sense, they compare the intertemporal marginal rate of substitution had not they been income constrained $\left(\frac{\lambda_{1 t+1}^{o}}{\lambda_{1 t}^{o}}\right)$ with the expected rate given their present rationing situation $\left(\frac{\lambda_{1 t+1}^{r}}{\lambda_{1 t}^{r}}\right)$. For example if, caeteris paribus, $\frac{\lambda_{1 t+1}^{o}}{\lambda_{1 t}^{o}}>\frac{\lambda_{1 t+1}^{r}}{\lambda_{1 t}^{r}}$ the whole third term in (54) is positive, indicating that $R o T$ 
individuals put additional pressure on the average reservation wage, as a way to ease their period by period constraint on consumption. The importance of this inequality term is positively related to the earning premium of being matched next period $\left(\frac{\lambda_{3 t+1}^{r}}{\lambda_{1 t+1}^{r}}\right)$, because it increases the value of a matching to continue in the future, and negatively related to the job finding probability $\left(\rho_{t}^{w}\right)$, that reduces the loss of breaking up the match.

Finally, fiscal variables also influence the division of the surplus rather than the definition of the worker's and the firm's threat points in the bargain. As commented earlier, the replacement rate increases the bargained wage because it raises income from unemployment. Both consumption and labour marginal taxes influence equilibrium wages because the imputed value of leisure is not taxed. An increase in either $\tau_{t}^{c}$ or $\tau^{l}$ make leisure more attractive in relation to work and, by doing so, increase wages in equilibrium. By contrast, an increase in social security contributions reduces wages by making recruiting an additional worker more expensive.

\subsection{Government}

Each period the government decides the size and composition of public expenditure and the mix of taxes and new debt holdings required to finance total expenditure. It is assumed that government purchases of goods and services $\left(g_{t}^{c}\right)$ and public investment $\left(g_{t}^{i}\right)$ follow an exogenously given pattern, while interest payments on government bonds $\left(1+r_{t}\right) b_{t-1}$ are model-determined, as well as unemployment benefits $g_{u t} s\left(1-n_{t-1}\right)$ and government social transfers $g_{s t}$ which are given by

$$
\begin{aligned}
g_{u t} & =\overline{r r} w_{t} \\
g_{s t} & =\overline{t r} g d p_{t}
\end{aligned}
$$

whereby $g_{u t}$ and $g_{s t}$ are indexed to the level of real wages, $w_{t}$, and activity, $g d p_{t}$, through $\overline{r r}$ and $\overline{t r}$.

Government revenues are made up of direct taxation on labour income (personal labour income tax, $\tau_{t}^{l}$, and social security contributions, $\left.\tau_{t}^{s c}\right)$ and capital income $\left(\tau_{t}^{k}\right)$, as well as indirect taxation, including a consumption tax at the rate $\tau_{t}^{c}$, and an energy tax at the rate $\tau_{t}^{e}$. Government revenues are therefore given by

$$
\begin{aligned}
t_{t}= & \left(\tau_{t}^{l}+\tau_{t}^{s c}\right) w_{t}\left(n_{t-1} l_{1 t}\right)+\tau_{t}^{k}\left(r_{t}-\delta\right) k_{t-1} \\
& +\tau_{t}^{c} \frac{P_{t}^{c}}{P_{t}} c_{t}+\tau_{t}^{e} \frac{P_{t}^{e}}{P_{t}} e_{t}+t r h_{t}+\tau_{t}^{l} \overline{r r} w_{t} s\left(1-n_{t-1}\right) l_{2 t}+\tau_{t}^{l} g_{s t}
\end{aligned}
$$

where $t r h_{t}$ stands for lump-sum transfers as defined further below.

Government revenues and expenditures each period are made consistent by means of the intertemporal budget constraint

$$
\gamma_{A} \gamma_{N} b_{t}=g_{t}^{c}+g_{t}^{i}+g_{u t} s\left(1-n_{t-1}\right) l_{2 t}+g_{s t}-t_{t}+\frac{\left(1+r_{t}^{n}\right)}{1+\pi_{t}} b_{t-1}
$$


Equation (59) reflects that the gap between overall receipts and outlays is financed by variations in lump-sum transfers to households, $t r h_{t}$ (which enter the fiscal budget rule through the term $t_{t}$ ), and/or debt issuance. Note that government cannot raise income from seniorage.

Dynamic sustainability of public debt requires the introduction of a debt rule that makes one or several fiscal categories an instrument for debt stabilization. In order to enforce the government's intertemporal budget constraint, the following fiscal policy reaction function is imposed

$$
t r h_{t}=t r h_{t-1}+\psi_{1}\left[\frac{b_{t}}{g d p_{t}}-\overline{\left(\frac{b}{g d p}\right)}\right]+\psi_{2}\left[\frac{b_{t}}{g d p_{t}}-\frac{b_{t-1}}{g d p_{t-1}}\right]
$$

where $\psi_{1}>0$ captures the speed of adjustment from the current ratio towards the desired target $\overline{\left(\frac{b}{g d p}\right)}$. The value of $\psi_{2}>0$ is chosen to ensure a smooth adjustment of current debt towards its steady-state level. Note that while in the baseline specification debt stabilization is achieved through variations in lump-sum transfers, other receipt and spending categories could also play this role.

Government investment (exogenous in the model) augments public capital, which, given the depreciation $\delta^{p}$, follows the law of motion:

$$
\gamma_{A} \gamma_{N} k_{t}^{p}=g_{t}^{i}+\left(1-\delta^{p}\right) k_{t-1}^{p}
$$

\subsection{Monetary policy}

Monetary policy is managed by the ECB via the following Taylor rule, which allows for some smoothness of the interest rate response to the inflation and output gap

$$
\ln \frac{1+r_{t}^{e m u}}{1+\overline{r^{e m u}}}=\rho^{r} \ln \frac{1+r_{t-1}^{e m u}}{1+\bar{r}^{e m u}}+\rho^{\pi}\left(1-\rho^{r}\right) \ln \frac{1+\pi_{t}^{e m u}}{1+\overline{\pi^{e m u}}}+\rho^{y}\left(1-\rho^{r}\right) \ln \Delta \ln y_{t}^{e m u}
$$

where all the variables with the superscript "emu" refer to EMU aggregates Thus, $r_{t}^{e m u}$ and $\pi_{t}^{e m u}$ are the euro-zone (nominal) short-term interest rate and inflation as measured in terms of the consumption price deflator and $\Delta \ln y_{t}^{e m u}$ measures the relative deviation of GDP growth from its trend. There is also some inertia in nominal interest rate setting. As discussed by Woodford (2003), (62) is the optimal outcome of a rational central bank facing an objective function, with output and inflation as arguments, in a general equilibrium setting.

The Spanish economy contributes to EMU inflation according to its economic size in the euro zone, $\omega_{S p}$ :

$$
\pi_{t}^{e m u}=\left(1-\omega_{S p}\right) \overline{\pi_{t}^{r e m u}}+\omega_{S p} \pi_{t}
$$

where $\overline{\pi_{t}^{r e m u}}$ is average inflation in the rest of the Eurozone. 
The disappearance of national currencies since the inception of the monetary union means that the intra-euro-area real exchange rate is given by the ratio of relative prices between the domestic economy and the remaining EMU members, so real appreciation/depreciation developments are driven by the inflation differential of the Spanish economy vis-à-vis the euro area:

$$
\frac{\operatorname{rer}_{t+1}}{\operatorname{rer}_{t}}=\frac{1+\pi_{t+1}^{e m u}}{1+\pi_{t+1}}
$$

\subsection{The external sector}

The small open economy assumption implies that world prices and world demand are given from the perspective of the national economy. It also means that feedback linkages between the Spanish economy, EMU and the rest of the world are ignored. Another simplifying assumption concerns the nature of final and intermediate goods produced at home, which are all regarded as tradable.

\subsubsection{The allocation of consumption and investment between domestic and foreign produced goods}

Aggregate consumption and investment are CES composite baskets of home and foreign produced goods. Consumption and investment distributors determine the share of aggregate consumption (investment) to be satisfied with home produced goods $c_{h}$ and $i_{h}$, and foreign imported goods $c_{f}$ and $i_{f}$. The aggregation technology is expressed by the following CES functions:

$$
\begin{aligned}
& c_{t}=\left(\left(1-\omega_{c t}\right)^{\frac{1}{\sigma_{c}}} c_{h t}^{\frac{\sigma_{c}-1}{\sigma_{C}}}+\omega_{c t}^{\frac{1}{\sigma_{c}}}\left(c_{f t}\right)^{\frac{\sigma_{c}-1}{\sigma_{c}}}\right)^{\frac{\sigma_{C}}{\sigma_{c}-1}} \\
& i_{t}=\left(\left(1-\omega_{i t}\right)^{\frac{1}{\sigma_{i}}} i_{h t}^{\frac{\sigma_{i}-1}{\sigma_{i}}}+\omega_{i t}^{\frac{1}{\sigma_{i}}}\left(i_{f t}\right)^{\frac{\sigma_{i}-1}{\sigma_{i}}}\right)^{\frac{\sigma_{i}}{\sigma_{i}-1}}
\end{aligned}
$$

where $\sigma_{c}$ and $\sigma_{i}$ are the consumption and investment elasticities of substitution between domestic and foreign goods.

Each period, the representative consumption distributor chooses $c_{h t}$ and $c_{f t}$ so as to minimize production costs subject to the technological constraint given by (65). The Lagrangian of this problem can be written as:

$$
\begin{aligned}
& \min _{c_{h t}, c_{f t}}\left\{\left(P_{t} c_{h t}+P_{t}^{m} c_{f t}\right)\right. \\
& \left.+P_{t}^{c}\left[c_{t}-\left(\left(1-\omega_{c}\right)^{\frac{1}{\sigma_{c}}} c_{h t}^{\frac{\sigma_{c}-1}{\sigma_{c}}}+\omega_{c}^{\frac{1}{\sigma_{c}}}\left(c_{f t}\right)^{\frac{\sigma_{c}-1}{\sigma_{c}}}\right)^{\frac{\sigma_{c}}{\sigma_{c}-1}}\right]\right\}
\end{aligned}
$$


where $P_{t}$ and $P_{t}^{m}$ are respectively the prices of home and foreign produced goods. Note that $P_{t}^{c}$ represents both the price of the consumption good for households and the shadow cost of production faced by the aggregator.

The optimal allocation of aggregate consumption between domestic and foreign goods, $c_{h t}$ and $c_{f t}$, satisfies the following conditions:

$$
\begin{aligned}
& c_{h t}=\left(1-\omega_{c}\right)\left(\frac{P_{t}}{P_{t}^{c}}\right)^{-\sigma_{c}} c_{t} \\
& c_{f t}=\omega_{c}\left(\frac{P_{t}^{m}}{P_{t}^{c}}\right)^{-\sigma_{c}} c_{t}
\end{aligned}
$$

Proceeding in the same manner as with the investment distributor problem, similar expressions can be obtained regarding the optimal allocation of aggregate investment between domestic and foreign goods, $i_{h t}$ and $i_{f t}$

$$
\begin{aligned}
& i_{h t}=\left(1-\omega_{i}\right)\left(\frac{P_{t}}{P_{t}^{i}}\right)^{-\sigma_{i}} i_{t} \\
& i_{f t}=\omega_{i}\left(\frac{P_{t}^{m}}{P_{t}^{i}}\right)^{-\sigma_{i}} i_{t}
\end{aligned}
$$

\subsubsection{Price formation}

The price of domestically produced consumption and investment goods is the GDP deflator, $P_{t}$. In order to obtain the consumption price deflator, the demands for home and foreign consumption goods (68) and (69) need to be incorporated into the cost of producing one unit of aggregate consumption goods $\left(P_{t} c_{h t}+P_{t}^{m} c_{f t}\right)$. Bearing in mind that the unitary production cost is equal to the price of production, one can express the consumption and investment price deflators as a function of the GDP and import deflators

$$
\begin{aligned}
& P_{t}^{c}=\left(\left(1-\omega_{c t}\right) P_{t}^{1-\sigma_{c}}+\omega_{c t} P_{t}^{m 1-\sigma_{c}}\right)^{\frac{1}{1-\sigma_{c}}} \\
& P_{t}^{i}=\left(\left(1-\omega_{i t}\right) P_{t}^{1-\sigma_{i}}+\omega_{i t} P_{t}^{m 1-\sigma_{i}}\right)^{\frac{1}{1-\sigma_{i}}}
\end{aligned}
$$

The exogenous world price is a weighted average of the final and intermediate goods prices, $\overline{P F M}$ and $\bar{P}^{e}$, both expressed in terms of the domestic currency. Given the small open economy assumption, the relevant foreign price is defined as:

$$
P_{t}^{m}=\left(\widetilde{\alpha}_{e} \overline{P_{t}^{e}}+\left(1-\widetilde{\alpha}_{e}\right) \overline{P F M}_{t}\right)
$$

where $\widetilde{\alpha}_{e}$ stands for the ratio of energy imports to overall imports.

We assume that export prices set by Spanish firms deviate from competitors' prices in foreign markets, at least temporarily. This is known in the literature as the "pricingto-market hypothesis" and it is consistent with a model of monopolistic competition 
among firms where each firm regards its influence on other firms as negligible. To make this assumption operational, we consider a fraction of $(1-p t m)$ firms whose prices at home and abroad differ. The remaining ptm goods can be freely traded by consumers so firms set a unified price across countries (i.e., the law of one price holds). In light of the arguments above, the Spanish export price deflator is defined as

$$
P_{t}^{x}=P_{t}^{(1-p t m)}\left(\overline{P F M}_{t}\right)^{p t m}
$$

where $P_{t}^{x}$ is the export price deflator, $\overline{P F M}_{t}$ is the competitors' price index expressed in euros and the parameter $\mathrm{ptm}$ determines the extent to which there is pricing-to-market.

\subsubsection{Exports and imports}

The national economy imports two final goods, consumption and investment, and one intermediate commodity, energy:

$$
i m_{t}=c_{f t}+i_{f t}+\alpha_{e} e_{t}
$$

where $\alpha_{e}$ represents the ratio of energy imports over total energy consumption.

Exports are a function of aggregate consumption and investment abroad, $\bar{y}_{t}^{w}$, and the ratio of the export price deflator to the competitors price index (expressed in euros), $P_{t}^{x} / \overline{P F M}_{t}$ :

$$
e x_{t}=s_{t}^{x}\left(\frac{P_{t}^{x}}{\overline{P F M}_{t}}\right)^{-\sigma_{x}} \bar{y}_{t}^{w}
$$

where $\sigma_{x}$ is the long-run price elasticity of exports. Plugging (75) into (77) yields the exports demand for a small open economy under the pricing-to-market hypothesis:

$$
e x_{t}=s_{t}^{x}\left(\frac{\overline{P F M}_{t}}{P_{t}}\right)^{(1-p t m) \sigma_{x}} \bar{y}_{t}^{w}
$$

Note that with full pricing to market $\mathrm{ptm}=0, P_{t}^{x}=P_{t}$ and expression (77) simplifies to

$$
e x_{t}=s_{t}^{x}\left(\frac{P_{t}}{P_{t}^{m}}\right)^{-\sigma_{x}} \bar{y}_{t}^{w}=s_{t}^{x}\left(\frac{P_{t}}{\overline{P F M}_{t}}\right)^{-\sigma_{x}} \bar{y}_{t}^{w}
$$

Conversely, if the law of one price holds for all consumption and investment goods, then $p t m=1, P_{t}^{x}=P_{t}^{m}=\overline{P F M}_{t}$ and expression (77) simplifies to

$$
e x_{t}=s_{t}^{x} \bar{y}_{t}^{w}
$$


Thus if the law of one price holds, exports are a sole function of total aggregate consumption and investment from abroad. Under full pricing to market $(\mathrm{ptm}=0)$, exports are also a function of relative prices with elasticity $\sigma_{x}$. Under the more general case of partial pricing-to-market $(0<p t m<1)$, the price elasticity of exports is given $(1-p t m) \sigma_{x}$.

\subsubsection{Stock-flow interaction between the current account balance and the accumulation of foreign assets}

In the model, the current account balance is defined as the trade balance plus net factor income from abroad (i.e., interest rate receipts/payments from net foreign assets):

$$
c a_{t}=\frac{P_{t}^{x}}{P_{t}} e x_{t}-\frac{P_{t}^{m}}{P_{t}} i m_{t}+\left(r_{t}^{e m u}-\pi_{t}\right) b_{t-1}^{o e m u}
$$

Following standard practice in the literature (see, for example, Obstfeld and Rogoff 1995, 1996), net foreign assets are regarded as a stock variable resulting from the accumulation of current account flows. This is illustrated by the following dynamic expression:

$$
\frac{\gamma_{A} \gamma_{N} b_{t}^{\text {oemu }}}{\phi_{b t}}=\frac{\left(1+r_{t}^{e m u}\right)}{1+\pi_{t}^{c}} b_{t-1}^{\text {oemu }}+\frac{P_{t}^{x}}{P_{t}} e x_{t}-\frac{P_{t}^{m}}{P_{t}} i m_{t}
$$

Equation (82) is obtained by combining the Ricardian households' budget constraint (assuming a zero net supply for domestic bonds and money), the government's budget constraint and the economy's aggregate resource constraint.

\subsection{Accounting identities in the economy}

Gross output can be defined as the sum of (final) demand components and the (intermediate) consumption of energy:

$$
y_{t}=c_{h t}+i_{h t}+g_{t}^{i}+g_{t}^{c}+\frac{P_{t}^{x}}{P_{t}} e x_{t}+\kappa_{v} v_{t}+\frac{P_{t}^{e}}{P_{t}}\left(1-\alpha_{e}\right) e_{t}+\kappa_{f}
$$

where, in line with definitions above (68) and (70), $c_{h t}$ and $i_{h t}$ are equal to overall domestic consumption and investment minus consumption and investment goods imported from abroad, and $\kappa_{f}$ is an entry cost which ensures that extraordinary profits vanish in imperfectly competitive equilibrium in the long-run. Value added generated in the economy is given by:

$$
g d p_{t}=y_{t}-\frac{P_{t}^{e}}{P_{t}} e_{t}-\kappa_{f}-\kappa_{v} v_{t}
$$




\section{Model solution method and parameterization}

\subsection{Model solution method}

The number of equations involved in the model and the presence of non-linearities do not allow for a closed-form solution for the dynamic stable path. In order to provide a solution for dynamic systems of this nature it has become a common procedure in the literature to use a numerical method. There are several ways of solving forwardlooking models with rational expectations. Most of them rely on algorithms that are applied to the linearized version of the system around the steady state. This approach, which is very popular in the literature, was first introduced by Blanchard and Kahn (1980).

In order to solve the model we follow the method developed by Laffarque (1990), Boucekkine (1995) and Juillard (1996). As various endogenous variables in the model have leads, representing expectations of these variables in future time periods, an assumption has to be made regarding the formation of expectations. In REMS expectations are rational and, therefore, model-consistent. This means that each period's future expectations coincide with the model's solution for the future. In simulations this implies that the leads in the model equations are equal to the solution values for future periods. This rational expectations solution is implemented by applying a stacked-time algorithm that solves for multiple time periods simultaneously, i.e., it stacks the time periods into one large system of equations and solves them simultaneously using Newton-Raphson iterations. The method is robust because the number of iterations is scarcely affected by convergence criteria, the number of time periods or the size of the shock. The model is simulated using the Dynare software system.

REMS obeys the necessary local condition for the uniqueness of a stable equilibrium in the neighbourhood of the steady state, i.e., there are as many eigenvalues larger than one in modulus as there are forward-looking variables in the system.

\subsection{The database REMSDB}

The database REMSDB includes the main Spanish economic aggregates (see Boscá et al. 2007, for further details). The complete set of series covers the period 1980-2010, which in turn can be divided into two sub-periods depending on the nature of the data. The first one ranges from 1980 to the last available data released by the various statistical sources, i.e., 2007 in the current version of the database. The second one, which spans over a 5-year period, relies on the official forecasts reflected in the Stability and Growth Programme (SGP). In the existing version of REMSDB the last available year of the forecast period corresponds to 2010. Finally, in order to generate a baseline scenario for the REMS model, the whole set of variables are extended forward until 2050. Such data extrapolation complies with the balanced-growth hypothesis of the model.

All series are quarterly data. In most cases, data on a quarterly basis were readily available from the existing statistical sources. Annual series were transformed into quarterly by applying the Kalman filter and smoother to an appropriate state-space 
model in which observations correspond to low-frequency data. Monthly series were converted into quarterly data with techniques that are specific to each series. All series take the form of seasonally adjusted data. Whenever the series provided by official statistical sources were not so, they were seasonally adjusted through TRAMO-SEATS procedures.

The data compiled in REMSDB has generally not been subject to any transformation other than the extraction of the seasonal component or the mere application of linking-back techniques. The group of variables used to construct the baseline scenario have nevertheless been expressed in efficiency units in order to ensure the stationary property.

The database considers five types of variables. While each of these groups is somewhat stylized, they gather a set of variables of a different nature. The first category includes production and demand aggregates and their deflators. A second group brings together population and labour-market series. The third block is made up of monetary and financial variables, whereas the fourth one includes aggregates of the general government. A final group gathers a number of heterogeneous variables used in the baseline scenario and for which no direct statistical counterpart is available from official sources.

\subsection{Model parameterization}

Model parameters have been fixed using a hybrid approach of calibration and estimation. Some parameter values are taken from QUEST II and other related DGE models. Several other parameters are obtained from steady-state conditions. The remaining parameters have been estimated on the basis of selected model's equations. Altogether, these parameters produce a baseline solution that accurately resembles the behaviour of the Spanish economy over the last two decades.

The data used for calibration purposes come from the REMSDB database and cover the period 1985:3 2006:4, during which the behaviour of endogenous variables complies with cyclical empirical regularities (see Puch and Licandro 1997; Boscá et al. 2007). The group of variables without statistical counterpart in official sources include consumption and employment of RoT and optimizing consumers, the Lagrange multipliers, the Tobin's $q$, the composite of private physical capital and energy, marginal cost and total factor productivity. These variables are computed using their corresponding behavioural equations in the model.

Table 1 lists the values of parameters and exogenous variables. The implied steady state values of the endogenous variables are given in Table $2 .{ }^{12}$ Broadly speaking, the calibration strategy follows a sequence by which we start by setting the value of a number of parameters which are subsequently used to obtain a measure of the level of total factor productivity. This makes it possible to express all variables in the model in terms of efficiency units. The remaining parameters are then fixed on the basis of the model's equations with variables measured in efficiency units.

\footnotetext{
12 The model has been programmed in relative prices. This means that nominal variables are normalized with, $P_{t}$, the price deflator of domestic final goods.
} 
Table 1 Parameter values

\begin{tabular}{llllllll}
\hline$\theta$ & 0.5400 & $\gamma$ & 1.75 & $\kappa_{f}$ & 0.129148 & $\rho^{w}$ & 0.75 \\
$\alpha$ & 0.59387 & $\rho^{r}$ & 0.75 & $\overline{P F M}$ & 1.002991 & $\phi_{e}$ & 25 \\
$\zeta$ & 0.06 & $\overline{\left(\frac{b}{g d p}\right)}$ & 2.40 & $\bar{y}^{w}$ & 7.306437 & $\rho_{e}$ & 0.85 \\
$\delta$ & 0.01587 & $\overline{r r}$ & 0.20225 & $T$ & 1.369 & $s$ & 0.269341 \\
$\delta^{p}$ & 0.01058 & $\tau^{l}$ & 0.110766 & $\chi_{m}$ & 0.20347 & $\phi_{b}$ & 0.006 \\
$\kappa_{v}$ & 0.18414 & $\tau^{k}$ & 0.208272 & $s^{x}$ & 0.021345 & $p t m$ & 0.57675 \\
$\sigma$ & 0.08625 & $\tau^{c}$ & 0.106985 & $\omega_{c}$ & 0.1395 & $\lambda^{w}$ & 0.42743 \\
$\chi_{1}$ & 0.61158 & $\tau^{s c}$ & 0.221531 & $\omega_{i}$ & 0.423765 & $\overline{m c}$ & 0.840691 \\
$\chi_{2}$ & 0.57257 & $\tau^{e}$ & 0.20 & $\lambda^{r}$ & 0.5 & $\sigma_{c}$ & 1.20548 \\
$\overline{l_{2}}$ & 0.21828 & $\psi_{1}$ & 0.01 & $h^{o}$ & 0.6 & $\sigma_{x}$ & 1.3 \\
$\phi_{1}$ & 3.23775 & $\psi_{2}$ & 0.2 & $h^{r}$ & 0.0 & $\sigma_{i}$ & 0.93043 \\
$\phi_{2}$ & 2.59905 & $\eta$ & 2.0 & $\alpha_{e}$ & 0.498 & $\lambda$ & 0.2006 \\
$\rho$ & 0.99776 & $\gamma_{A}$ & 1.00170 & $\widetilde{\alpha}_{e}$ & 0.10489 & $\beta^{f}$ & 0.4965 \\
$a$ & 0.99888 & $\gamma_{N}$ & 1.00325 & $\overline{t r}$ & 0.138154 & $\beta^{b}$ & 0.5035 \\
$\phi$ & 5.50 & $r^{n w}$ & 0.0142 & $\overline{t r h}$ & 0.0259859 & $\omega_{S p}$ & 0.1000 \\
\hline
\end{tabular}

Table 2 Steady state

\begin{tabular}{llllllll}
\hline$b_{t}$ & 1.4207 & $i_{h t}$ & 0.0787 & $\lambda_{3 t}^{r}$ & 1.5633 & $g_{s t}$ & 0.0818 \\
$b_{t}^{o}$ & 1.4207 & $i m_{t}$ & 0.1542 & $\lambda_{t}^{n d}$ & 0.5119 & $t_{r} h_{t}$ & 0.0326 \\
$c_{t}$ & 0.3618 & $j_{t}$ & 0.1408 & $\lambda_{1 t}^{o}$ & 2.2221 & $t_{t}$ & 0.2104 \\
$c_{f t}$ & 0.0633 & $j_{t}^{o}$ & 0.2816 & $\lambda_{1 t}^{r}$ & 3.1218 & $g_{u t}$ & 0.2724 \\
$c_{h t}$ & 0.2999 & $\rho_{t}^{w}$ & 0.0732 & $\frac{p_{t}^{c}}{p_{t}}$ & 0.9694 & $v_{t}$ & 0.1120 \\
$c_{t}^{o}$ & 0.4251 & $k_{t}$ & 6.7604 & $\pi_{t}$ & 0.0000 & $w_{t}$ & 1.5147 \\
$c_{t}^{r}$ & 0.2985 & $k e_{t}$ & 5.7032 & $g d p_{t}$ & 0.5920 & $\widetilde{w}_{t}$ & 1.5147 \\
$e_{t}$ & 0.0402 & $k_{t}^{o}$ & 13.521 & $\pi_{t}^{c}$ & 0.0000 & $y_{t}$ & 0.7764 \\
$r e r_{t}$ & 0.8157 & $k_{t}^{p}$ & 1.1028 & $\frac{p_{t}^{i}}{p_{t}}$ & 0.9119 & $z_{t}$ & 1.0000 \\
$e x_{t}$ & 0.1394 & $m_{t}$ & 3.2536 & $\frac{p_{t}^{m}}{p_{t}}$ & 0.8037 & $g_{t}^{i}$ & 0.0171 \\
$b_{t}^{w}$ & 0.0000 & $\widehat{m c}$ & 0.0000 & $\frac{p_{t}^{x}}{p_{t}}$ & 0.8892 & & \\
$b_{t}^{o w}$ & 0.0000 & $m_{t}^{o}$ & 6.5072 & $q_{t}$ & 1.0164 & & \\
$g_{t}^{c}$ & 0.0895 & $n_{t}$ & 0.4499 & $r_{t}$ & 0.0331 & & \\
$l_{1 t}$ & 0.4369 & $n_{t}^{o}$ & 0.4499 & $r_{t}^{n}$ & 0.0142 & & \\
$i_{t}$ & 0.1489 & $n_{t}^{r}$ & 0.4499 & $\phi_{b t}$ & 1.0000 & & \\
$i_{f t}$ & 0.0709 & $\lambda_{3 t}^{o}$ & 0.1560 & $l_{2 t}$ & 0.2183 & & \\
\hline
\end{tabular}

The Cobb-Douglas parameter $\alpha$ matches the average value of the labour share in the data, as measured by the ratio of compensation of employees to GDP. The public capital elasticity of output, $\zeta$, has been set at 0.06 , which falls within the range of the estimated values reported by Gramlich (1994). Given the values of $\alpha$ and $\zeta$ it is straightforward to obtain the level of technological efficiency, $A_{t}$, using expression 
(31). HP-filtered total factor productivity is then used to rescale all variables with respect to efficiency. Technical progress, $\gamma_{A}$, is given by the growth rate of trend productivity.

The calibrated values of a number of parameters are taken from QUEST II. This is the case of the subjective discount rate, $\beta$, the parameter of adjustment costs in the investment function, $\phi$, the long-run price elasticity of exports, $\sigma_{x}$, and fiscal rule parameters, $\psi_{1}$ and $\psi_{2}$.

Following Andolfatto (1996), we choose a value of 2 for parameter defining the degree of intertemporal labour substitution, $\eta$, whereas the amount of time devoted to looking for a job, $\overline{l_{2}}$, is estimated as half as much the quarterly average of working time. $\kappa_{v}$ is calibrated to match an overall cost of vacant posts equal to $0.5 \%$ points of GDP. As in Burnside et al. (1993) we fix total productive time endowment $T$ at 1.369 (thousand) hours per quarter. The exogenous job destruction rate, $\sigma$, is calibrated from the law of motion of the employment (4). The share of non-employed workers actively searching for a job, $s$, is obtained from the ratio between the unemployment rate and one minus the employment rate, $(1-n)$.

We follow Doménech et al. (2002) in calibrating the parameters that enter the monetary policy reaction function $\gamma_{E M U}$ and $\rho_{E M U}^{r}$. The weight of the Spanish economy in the euro-zone inflation, $\omega_{S p}$, is set at $10 \%$. The public debt to GDP target ratio has been set at 2.4. This corresponds to a $60 \%$ value on an annual basis, which is equal to the limit established in the Stability and Growth Pact. Tax rates on labour and capital income and consumption expenditure $\left(\tau^{l}, \tau^{k}, \tau^{s c}, \tau^{c}\right)$ have been constructed following the methodology developed by Boscá et al. (2005). Tax rate on energy, $\tau_{t}^{e}$, has been set at 0.20 . The growth rate of population, $\gamma_{N}$, has been computed on the basis of working-age population data. We use the ratio of unemployment benefits to labour compensation to calibrate the replacement rate, $\overline{r r}$.

The value of 0.6 for $h^{o}$, the parameter that captures habits in consumption of $\mathrm{Ri}$ cardian households, has been taken from Smets and Wouters (2003). The fraction of $R o T$ consumers in the Spanish economy, $\lambda^{r}$, is assumed to be 0.5 which is a quite standard value. The risk premium parameter, $\phi_{b}$, is fixed at 0.006 . This is somewhat higher than the value in Erceg et al. (2005), implying faster convergence of the foreign asset position to the steady state. The scale parameter of the matching function, $\chi_{1}$, and the elasticity of matchings with respect to vacant posts, $\chi_{2}$, have been estimated at, respectively, 0.61 and 0.57 , respectively. In line with the efficiency condition in Hosios (1990), the workers' bargaining power is set at $1-\chi_{2}$.

The entry cost, $\kappa_{f}$, is calculated at 0.13 from a markup of $20 \%$. Using data on the weight of intermediate inputs in gross output from the Input-Output tables, the distributional parameter in the energy-capital composite, $a$, has been set to 0.99. The estimated value of $\rho$ is 0.99 , which corresponds to an elasticity of substitution $1 /(1+\rho)$ of 0.50 , implying that private capital and energy are complements in production. Value added is then computed using the accounting identity (84). The ratio of energy imports to total energy consumption, $\alpha_{e}$, is taken from the Input-Output Tables (year 2000). Private and public capital depreciation $\delta$ and $\delta^{p}$ are the rates implicit in the capital series in BDREMS, respectively around 6 and $4 \%$ per year.

As regards preference parameters in the households utility function, $\phi_{1}$ and $\phi_{2}$, the former is estimated from the hours schedule Eq. (55), whereas the latter has been 
computed as a weighted average (with weights $\lambda^{r}$ and $\left(1-\lambda^{r}\right)$ ) of the estimates arising from the two labour supply conditions, (8) and (23). Overall, our values for $\phi_{1}$ and $\phi_{2}$ resemble those obtained by Andolfatto (1996) and other related research in the literature, implying that the imputed value for leisure by an employed worker is situated well above the imputed value for leisure by an unemployed worker.

We use the employment demand (39) to obtain a series for the firm's marginal cost, $m c_{t}$. The steady state value, $\overline{m c}$, is set at the sample mean. We choose the degree of price indexation $\varkappa$ at 1 (hypothesis testing of an estimated value of 1 for $\varkappa$ results in no rejection), and use expression (49) to obtain a GMM estimation of the fraction of non-optimizing firms, $\theta$. The estimated value is equal to 0.54 . Together with the subjective discount rate, these two parameters imply a value of 0.20 for the marginal cost elasticity of inflation, $\lambda,{ }^{13}$ and 0.50 for the weights attached to the forward and backward components of inflation, $\beta^{f}$ and $\beta^{b}$. Values of these parameters about one half are a key feature of the hybrid Phillips curve with full indexation, as evidenced by the empirical literature. ${ }^{14}$

In the external sector, we have used Eqs. (75) and (74) to obtain estimations of the pricing-to-market parameter, ptm, and the ratio of energy imports to overall imports, $\widetilde{\alpha}_{e}$. Our estimate for $\widetilde{\alpha}_{e}$ suggests that energy represents around $10 \%$ of total imports. The estimated value of $\mathrm{ptm}$ parameter (0.58) is of the same order of magnitude as in QUEST II (0.61). The weight of domestic consumption goods in the CES aggregator, $\omega_{c}$, and the consumption elasticity of substitution between domestic and foreign goods, $\sigma_{c}$, are estimated simultaneously using conditions (68) and (69). Similarly, for the case of investment goods, $\omega_{i}$ and $\sigma_{i}$ are estimated simultaneously using Eqs. (70) and (71). The estimated elasticities suggest a slightly higher elasticity of substitution between domestic and foreign goods for consumption goods as compared with investment goods. We use the export equation (77) to calibrate the scale parameter $s^{x}$. The energy price index, $P^{e}$, and the world price index, $\overline{P F M}$, match sample averages calculated over the calibration period.

The value of two parameters has been accommodated to ensure the desirable longrun properties of the model. The world interest rate, $\overline{r^{e m u}}$, is set to satisfy the static version of Eq. (11), so that the current account is balanced in the steady state. Second, foreign output, $\bar{y}^{w}$, is adjusted to obtain a steady state value of the real exchange rate close to the observed one.

Finally, the value of a number of parameters has been chosen for labour market variables to display plausible dynamic patterns. Namely, we assume partial inertia in the search effort, $\rho_{e}$. As in Blanchard and Galí (2006), we allow for slow adjustment in wages, which evolve according to the expression $w_{t}=w_{t-1}^{\rho^{w}} \widetilde{w}_{t}^{\left(1-\rho^{w}\right)}$, with $\widetilde{w}_{t}$ being the Nash-bargained wage. This hypothesis is introduced in the model in an ad hoc manner, with an estimated value of $\rho^{w}=0.75$.

\footnotetext{
13 This value is significantly higher than that obtained by Galí and Lopez-Salido (2001).

14 Bils and Klenow (2004) find that the average duration between price adjustments is over six months. The evidence on price setting in the euro area at the individual level by Álvarez et al. (2006) shows that prices in the euro area are stickier than in the US.
} 

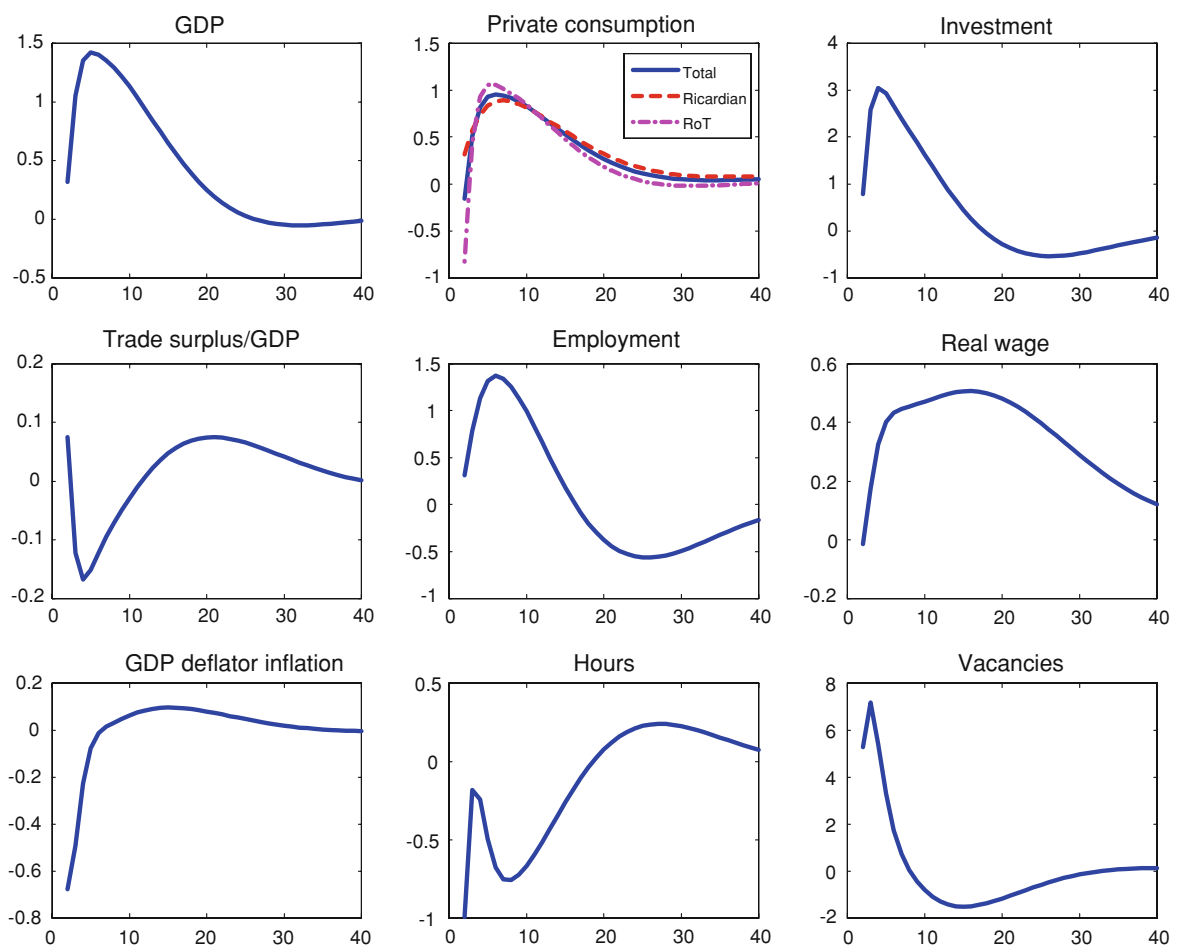

Fig. 1 Effects of a transitory technological shock

\section{Simulations}

This section shows the properties of the model and examines the basic transmission channels at work by presenting some simulation exercises. First, we show results of two standard simulated scenarios, a technology shock and a public consumption shock. The two shocks are of a temporary nature and fully anticipated by economic agents. Finally, we end this section with the simulated short and long-run impacts on some macroeconomic variables of a menu of fiscal policies.

\subsection{A transitory technology shock}

In this section an exogenous productivity improvement is implemented as a $1 \%$ increase of $z_{i}$. The technology shock is modelled as a first-order autoregressive process with a persistence parameter of 0.9 , implying that the level of total factor productivity after 5 years is situated $0.2 \%$ points above the steady state level.

Figure 1 displays the (quarterly) dynamic responses of selected macroeconomic variables in the model. Simulation results are percentage deviations from baseline, except for the trade surplus and the GDP deflator inflation, which are absolute deviations. 
Fig. 2 Effects of a technology shock on full-time equivalent employment

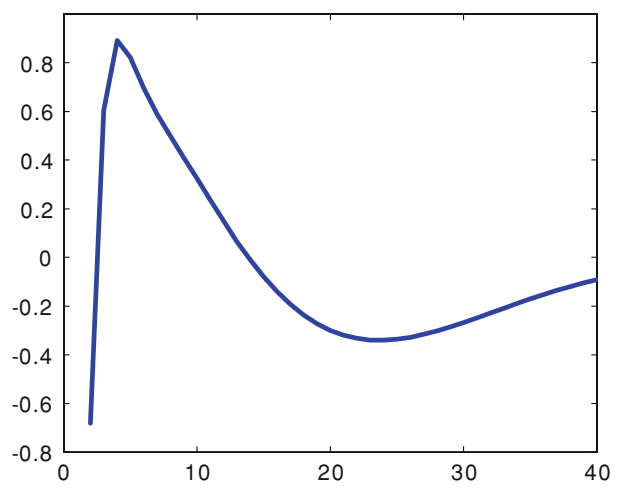

Figure 1 shows that the multiplier on GDP on impact is close to one third. The GDP effect is quite persistent, reaching a peak after four quarters. There are also positive and long-lasting effects on consumption, investment and wages. Slow adjustment in Nash-bargained wages is reflected in a positive albeit muted effect on wages, which generates a marked response in employment. The shock also leads to an increase in consumption, which peaks after five quarters. Hump-shaped consumption dynamics is explained by the presence of $R o T$ households, which display relatively more volatile and less persistent consumption compared with Ricardians. It is worth mentioning that our impulse-response functions closely resemble those presented in Andrés et al. (2008) who, extending the research of Andrés and Doménech (2006), also find small effects in the very short run following a technology shock in the context of a model with price rigidities and $R o T$ consumers.

As expected, the technology shock has a sizable effect on marginal costs (not shown in the graph), which fall on impact, thereby increasing the Tobin's $q$ and stimulating capital accumulation through investment. Also, the fall in marginal costs moderates inflation, improves price competitiveness and encourages export demand. However, the booming in domestic absorption accelerates imports and more than offsets the positive effect of the real depreciation on the trade balance in the short run.

The effect on vacancies is quite pronounced. To give an order of magnitude, note that the response of vacancies on impact is more than 10 times as large as that of GDP. This result is explained by the positive impact that enhanced GDP growth has on search effort. Moreover, our model can account for the evidence documented by Fujita (2004) and Ravn and Simonelli (2007), whereby vacancies display a humpshaped pattern and peak around 3 quarters after the shock. In our model, following the initial positive response, vacancies register an increase to afterwards decline as labour market becomes tighter. Although short-lived, the increase in vacancies encourages job creation and employment, whose effects are more persistent as explained further below.

The behaviour of (full-time-equivalent) employment is plotted in Fig. 2. The dynamics of this variable is in sharp contrast with the pattern implied by a standard RBC model with flexible prices. In presence of price rigidities, responses in both the intensive and the extensive margins of labour differ in direction and size. While the employment rate 

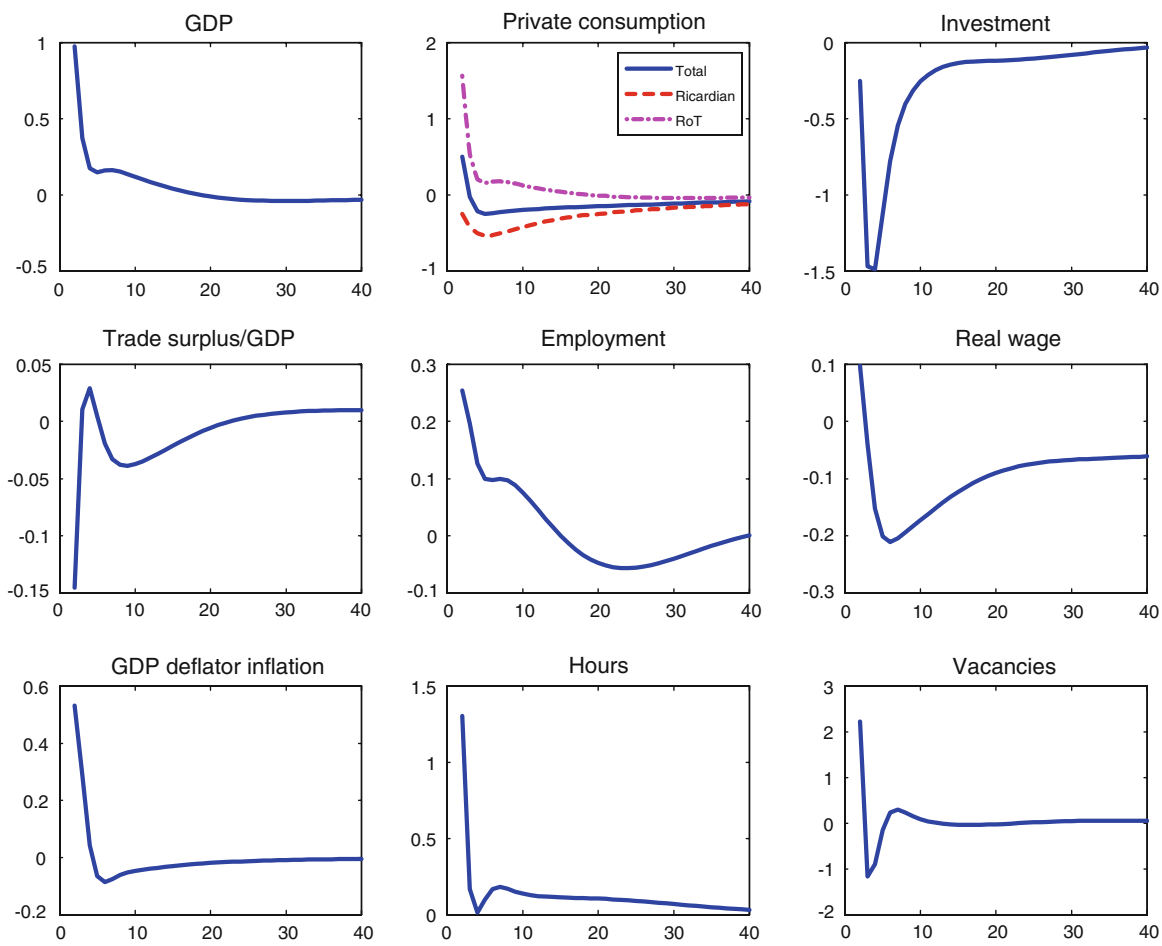

Fig. 3 Effects of a transitory public consumption shock

rises over time, hours per worker sharply falls on impact. Overall, (full-time equivalent) employment falls over the first four quarters, and only attains pre-shock levels after 1 year. These predictions match the empirical findings of a growing literature beginning with Galí (1999) (see, for instance, Section 2 in Galí and Rabanal 2004 and Andrés et al. 2008, for an overview of research studies with similar conclusions).

\subsection{A transitory public consumption shock}

With a view to illustrate further transmission channels in REMS, this section discusses an exogenous transitory shock affecting the steady-state level of public consumption. The fiscal impulse amounts to $1 \%$ of baseline GDP (or $6.5 \%$ of $g^{c}$ ) and it is assumed to follow a first-order autoregressive process with a persistence parameter of 0.9 . Figure 3 displays the quarterly dynamic responses of the main macroeconomic variables in the model.

The multiplier on GDP $\left(\Delta \mathrm{GDP} / \Delta g^{c}\right)$ on impact is equal to 1. A transitory impulse to public consumption leads to a significant increase in consumption (by around $0.5 \%$ points on impact), that lasts for about two quarters. This is confirmed by existing evidence of models allowing for liquidity-constrained (see Blanchard and Galí 2006; Galí et al. 2007). As suggested by the second panel in Fig. 3, the dynamics of overall consumption is largely driven by the behaviour of RoT households, whose consumption 
Fig. 4 Effects of a public consumption shock on full-time equivalent employment

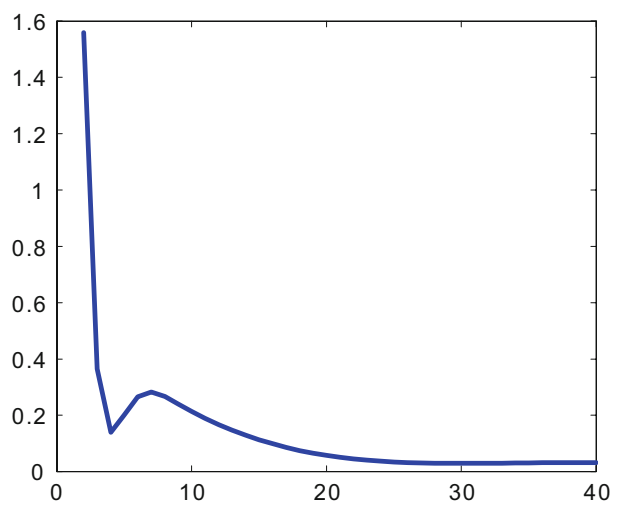

increases on impact by more than $1 \%$ point. In contrast, optimizing households, which are fully aware of the transitory nature of the shock, revise their current consumption downwards to offset the negative effect of the fiscal stimulus on government savings.

Private investment falls immediately after the shock and continues dropping up to $1.5 \%$ after three to four quarters, suggesting a sizable crowding-out effect. The trough in investment can be rationalized in terms of a decline in Tobin's $q$, a slightly higher euro-zone nominal interest rate (as higher inflation and output gaps in the Spanish economy affect the corresponding euro-zone variables in a proportion determined by the weight of the domestic economy in the euro area), and a higher risk premium. The latter results in a lower level of external debt hold by domestic households.

Figure 3 shows that employment, hours, real wages and vacancies increase on impact, then gradually return to normal. The jump in vacant posts is explained by improved search effort and a higher shadow price of employment, $\lambda^{\text {nd }}$. Full-time equivalent employment (see Fig. 4) is enhanced by the positive response of employment both in terms of headcounts and hours worked.

\subsection{Choosing among different fiscal policies}

We use now REMS to simulate the short (Table 3) and long run effects (Table 4) of performing different fiscal policy measures. In all cases we show the impact on GDP, employment and the ratio of public debt to GDP. Thus, we analyse the effects of a $1 \%$ point reduction in the effective labour tax rate (row 1 ), of a $1 \%$ point reduction in the effective consumption tax rate (row 2), of a 1\% GDP increase in public consumption (row 3) and of a 1\% GDP increase in public investment (row 4). Finally, in row 5 we take into account the proposal of Fernández-Villaverde and Rubio-Ramírez (2009) simulating the effects of a $2 \%$ point reduction in the labour tax rate, together with a $1 \%$ point increase in the consumption tax rate. According to their results a $1 \%$ point reduction in the effective labour tax rate in Spain would increase GDP on impact by $1.076 \%$, whereas a $1 \%$ point reduction in the effective consumption tax rate would cause a rise in GDP of $0.175 \%$. Both measures taken together, which constitute their preferred policy-mix, would increase GDP by about $2 \%$ on impact. Surprisingly their 
Table 3 Fiscal policies (1 year multiplier)

\begin{tabular}{lllc}
\hline Economic policy measure & GDP & Employment & Public debt/GDP \\
\hline (1) Labour tax reduction (1\%) & 0.353 & 0.620 & 0.285 \\
(2) Consumption tax reduction (1\%) & 0.285 & 0.501 & 0.269 \\
(3) Public consumption increase (1\% of GDP) & 0.336 & 0.621 & 0.137 \\
(4) Public investment increase (1\% of GDP) & 0.677 & 0.927 & -0.077 \\
(5) Fernández-Villaverde \& Rubio proposal & 0.421 & 0.737 & 0.302 \\
\hline
\end{tabular}

Table 4 Fiscal policies (long run multiplier)

\begin{tabular}{llll}
\hline Measure & GDP & Employment & Public debt/GDP \\
\hline (1) Labour tax reduction (1\%) & 0.54 & 0.59 & 0 \\
(2) Consumption tax reduction (1\%) & 0.44 & 0.48 & 0 \\
(3) Public consumption increase (1\% of GDP) & 0.94 & 0.85 & 0 \\
(4) Public investment increase (1\% of GDP) & 3.28 & 0.23 & 0 \\
(5) Fernández-Villaverde \& Rubio proposal & 0.64 & 0.69 & 0 \\
\hline
\end{tabular}

results show that increasing public investment $1 \%$ point would reduce GDP on impact a $1.124 \%$.

Our results are in contrast with those of Fernández-Villaverde and Rubio-Ramírez (2009). Looking at the 1 year multipliers in Table 3 (calculated as a simple average of simulated effects in the first four quarters), we find that public investment would generate the biggest effect both on GDP, that would increase a $0.677 \%$, and on employment, that would rise by almost $1 \%$ point. The Fernández-Villaverde and Rubio-Ramírez (2009) proposal is the second preferred option in the ranking of simulations performed with REMS, although with lower impact that the one calculated by these authors. Moreover, the cost of this proposal in terms of public debt is the highest one among all fiscal policy actions considered. In the long run, when the public debt to GDP ratio returns to its initial value, the primacy of public investment policies with respect to other ways of implementing fiscal policies is even more pronounced. Thus, our simulations give support to the recent government injection of 8,000 million euros to finance public investment (Plan E), when comparing its effects on GDP and employment with other fiscal measures based on transfers to households or tax cuts.

\section{Conclusions}

This paper presents a Rational Expectations Model for Simulation and Policy Evaluation of the Spanish Economy (REMS). REMS is a DGE model for a small open economy. It is primarily constructed to serve as a tool for simulation and policy evaluation of alternative scenarios. This means that REMS is not used for forecasting, but rather to analyse how the effects of policy shocks are transmitted over the medium 
term. It also means that the emphasis of the model is on the transmission channels through which policy action affects the domestic economy.

As far as economic theory is concerned, REMS can be characterized as a New Keynesian model with the optimizing behaviour of households and firms being deeply rooted in the Rational Expectations hypothesis. The supply side of the economy is modelled through a neoclassical production function, implying that the long-term behaviour of the model closely reproduces the Solow growth model, that is, the economy reaches a steady state path with a growth rate determined by the rate of exogenous technical progress plus the growth rate of the population. However, some prominent features differentiate this model from the neoclassical paradigm in the long term. First, trading both in the goods and the labour market is not achieved under Walrasian conditions. Firms in goods markets operate under monopolistic competition, setting prices in a sluggish manner. In the labour market, firms and workers negotiate how to distribute the rents generated in the matching process. Consequently, in our model equilibrium unemployment will persist in the long term. Second, a share of households behaves as myopic consumers that do not optimize intertemporally. Additionally, consumers take into account past consumption (habits) in their decisions. As a result, the behaviour of aggregate consumption after a fiscal shock departs considerably from what could be expected in a neoclassical setting. In the short term REMS is also influenced by the New Keynesian literature allowing for a stabilizing role of demand-side policies.

Nevertheless, the model still lacks sufficient detail to make a direct link between some specific reform efforts and economic performance. Several ways of improving the model are opened for the future. For instance, a weak point of the existing version of the model is that it is not detailed enough to differentiate across skill groups of the labour force. Also, REMS sticks on the exogenous nature of technical progress, whereas it is widely recognized by now that knowledge investment is a key to economic growth and there is a link between the growth rate of technical progress and R\&D spending. Moreover, as the recent financial crisis has made it clear a better understanding is needed of the linkages between the financial sector and the real sector. A final improvement of the model concerns estimation techniques. Forthcoming versions of REMS should estimate the model using Bayesian estimation techniques.

Acknowledgments This research could have not been accomplished without the unconditional support of Juan Varela. We would like to thank the helpful comments and suggestions of Javier Andrés, Pablo Burriel, Francisco Corrales, Ángel de la Fuente, Víctor Gómez, Luis González-Calbet, Campbel Leith, Ángel Melguizo, Eduardo Pedreira, Álvaro Sanmartín and participants at the workshop on Lisbon methodology organized by the EU Commission and at the XXXII SAE. The work of Andrés de Bustos with the dataset has been invaluable. Financial support from the European Regional Development Fund (ERDF) and Fundación Rafael del Pino is gratefully acknowledged. J. E. Boscá and J. Ferri also thank the financial support by CICYT Grants ECO2008-04669 and ECO2009-09569 and Luis Puch CICYT Grant SEJ2004-04579.

Open Access This article is distributed under the terms of the Creative Commons Attribution Noncommercial License which permits any noncommercial use, distribution, and reproduction in any medium, provided the original author(s) and source are credited. 


\section{References}

Adolfson M, Laséen S, Lindé J, Villani M (2007) Evaluating an estimated new Keynesian small open economy model. Working Paper Series 203. Sveriges Riksbank

Álvarez L, Dhyne E, Hoeberichts M, Kwapil C, Le Bihan H, Lünnemann P, Martins F, Sabbatini R, Stahl H, Vermeulen P, Vilmunen J (2006) Sticky prices in the Euro area: a summary of new microevidence. J Eur Econ Assoc 4(2-3):575-584

Andolfatto D (1996) Business cycles and labor-market search. Am Econ Rev 86(1):112-132

Andrés J, Burriel P, Estrada A (2006) BEMOD: a DSGE model for the Spanish economy and the rest of the Euro area. Banco de España Research Paper, No. WP-0631

Andrés J, Doménech R (2006) Automatic stabilizers, fiscal rules and macroeconomic stability. Eur Econ Rev 50(6):1487-1506

Andrés J, Doménech R, Fatás A (2008) The stabilizing role of government size. J Econ Dyn Control 32:571-593

Benigno P (2001) Price stability with imperfect financial integration. CEPR Discussion Paper No. 2854

Bils M, Klenow P (2004) Some evidence on the importance of sticky prices. J Political Econ 112(5):947985

Blanchard OJ, Galí J (2006) A new Keynesian model with unemployment. MIT Department of Economics Working Paper No. 06-22

Blanchard OJ, Kahn CM (1980) The solution of linear difference models under rational expectations. Econometrica 48:1305-1311

Boscá JE, García JR, Taguas D (2005) Tipos Efectivos de Gravamen y Convergencia Fiscal en la OCDE: 1965-2001. Hacienda Pública Española 174(3):119-141

Boscá JE, Bustos A, Díaz A, Doménech R, Ferri J, Pérez E, Puch L (2007) The REMSDB macroeconomic database of the Spanish economy. Working Paper WP-2007-04. Ministerio de Econom ía y Hacienda

Boucekkine R (1995) An alternative methodology for solving non linear forward-looking models. J Econ Dyn Control 19(4):711-734

Burnside C, Eichenbaum M, Rebelo S (1993) Labor hoarding and the business cycle. J Political Econ 101(2):245-273

Burriel P, Fernández-Villaverde J, Rubio J (2007) MEDEA: a Bayesian DSGE model for the Spanish economy. Economy Bureau of the Prime Minister, Spain

Cadiou L, Dées S, Guichard S, Kadareja A, Laffargue JP, Bronka R (2001) Marmotte. A multinational model by CEPII/CEPREMAP. CEPII Working paper No. 2001-15

Calvo G (1983) Staggered prices in a utility maximizing framework. J Monet Econ 12:383-398

Carlstrom CT, Fuerst TS (2001) Timing and real indeterminacy in monetary models. J Monet Econ 47:285298

Doménech R, Ledo M, Taguas D (2002) Some new results on interest rate rules in EMU and in the US. J Econ Bus 54(4):431-446

Erceg CJ, Guerrieri L, Gust C (2005) Expansionary fiscal shocks and the US trade deficit. Int Finance 8(3):363-397

Erceg CJ, Guerrieri L, Gust C (2006) SIGMA: a new open economy model for policy analysis. Int J Central Banking 2(1):1-50

Fernández-Villaverde J, Rubio-Ramírez J (2009) Una propuesta de política fiscal ante la crisis. In La Crisis de la Economía Española: Lecciones y Propuestas. FEDEA eBook

Fujita S (2004) Vacancy Persistence FRB of Philadelphia Working Paper No. 04-23

Galí J (1999) Technology, employment and the business cycle. Do technology shocks explain aggregate fluctuations? Am Econ Rev 89(1):249-271

Galí J, Lopez-Salido JD (2001) Una nueva Curava de Phillips para España. Moneda y Crédito 212:265-304

Galí J, Rabanal P (2004) Technology shocks and aggregate fluctuations: how well does the RBS model fit postwar U.S. data? NBER Working Paper No. 10636

Galí J, Gertler Galí, Lopez-Salido JD (2001) European inflation dynamics. Eur Econ Rev 45:1237-1270

Galí J, Lopez-Salido JD, Vallés J (2007) Understanding the effects of government spending on consumption. J Eur Econ Assoc 5(1):227-270

Gramlich EM (1994) Infrastructure investment: a review essay. J Econ Lit 32:1176-1196

Harrison R, Nikolov K, Quinn M, Ramsay G, Scott A, Thomas R (2005) The Bank of England quarterly model. Bank of England 
Hosios AJ (1990) On the efficiency of matching and related models of search unemployment. Rev Econ Stud 57:279-298

Juillard M (1996) Dynare: a program for the resolution and simulation of dynamic models with forward variables through the use a relaxation algorithm. CEPREMAP Working paper No. 9602

Kilponen J, Ripatti A, Vilmunen J (2004) AINO: the Bank Of Finland's new dynamic general equilibrium odel of the finnish economy. Bank Finland Bull 3:71-77

Laffarque JP (1990) Résolution d'un Modèle Macro économique avec Anticipations Rationneles. Ann Econ Stat 17:97-119

Lindé J, Nessén M, Söderström U (2004) Monetary policy in an estimated open-economy model with imperfect pass-through. Working Paper Series 167, Sveriges Riksbank

Merz M (1995) Search in the labor market and the real business cycle. J Monet Econ 36:269-300

Molinas C, Ballabriga C, Canadell E, Escribano A, López E, Manzanedo L, Mestre R, Sebastián y M, Taguas D (1990) MOISEES: un modelo de investigación y simulación de la economía española. Antoni Bosch, editor

Murchison S, Rennison A, Zhu Z (2004) A structural small open-economy model for Canada. Working Papers 04-4, Bank of Canada

Obstfeld M, Rogoff K (1995) Exchange rate dynamics redux. J Political Econ 103:624-660

Obstfeld M, Rogoff K (1996) Foundations of international macroeconomics. MIT Press, Cambridge

Pissarides CA (2000) Equilibrium unemployment theory. MIT Press, Cambridge

Puch L, Licandro O (1997) Are there any special features in the Spanish business cycle? Investig Econ XXI 2:361-394

Ravn MO, Simonelli S (2007) Labor market dynamics and the business cycle: structural evidence for the United States. CSEF Working Papers, 182

Schmitt-Grohe S, Uribe M (2003) Closing small open economy models. J Int Econ 61:163-185

Smets F, Wouters R (2003) An estimated dynamic stochastic general equilibrium model of the Euro area. J Eur Econ Assoc 1(5):1123-1175

Trigari A (2004) Labour market search, wage bargaining and inflation dynamics. Working Papers 268, IGIER

Turnovsky SJ (1985) Domestic and foreign disturbances in an optimizing model of exchange-rate determination. J Int Money Finance 4(1):151-171

Woodford M (2003) Interest and prices, foundations of a theory of monetary policy. Princeton University Press, Princeton 